\title{
Civil society involvement in family planning: A review of global programming and evidence
}

Victoria Boydell

Robin Keeley

Kumudha Aruldas

Karen Hardee

Follow this and additional works at: https://knowledgecommons.popcouncil.org/departments_sbsr-rh How does access to this work benefit you? Let us know!

\section{Recommended Citation}

Boydell, Victoria, Robin Keeley, Kumudha Aruldas, and Karen Hardee. 2017. "Civil society involvement in family planning: A review of global programming and evidence," Research report. Washington, DC:

Population Council, The Evidence Project. 
Civil Society Involvement in Family Planning

0
11
0
11
0
0
0
0
0
0
0
0

Victoria Boydell

Robin Keeley

Kumudha Aruldas

Karen Hardee

and Evidence

DECEMBER 2017

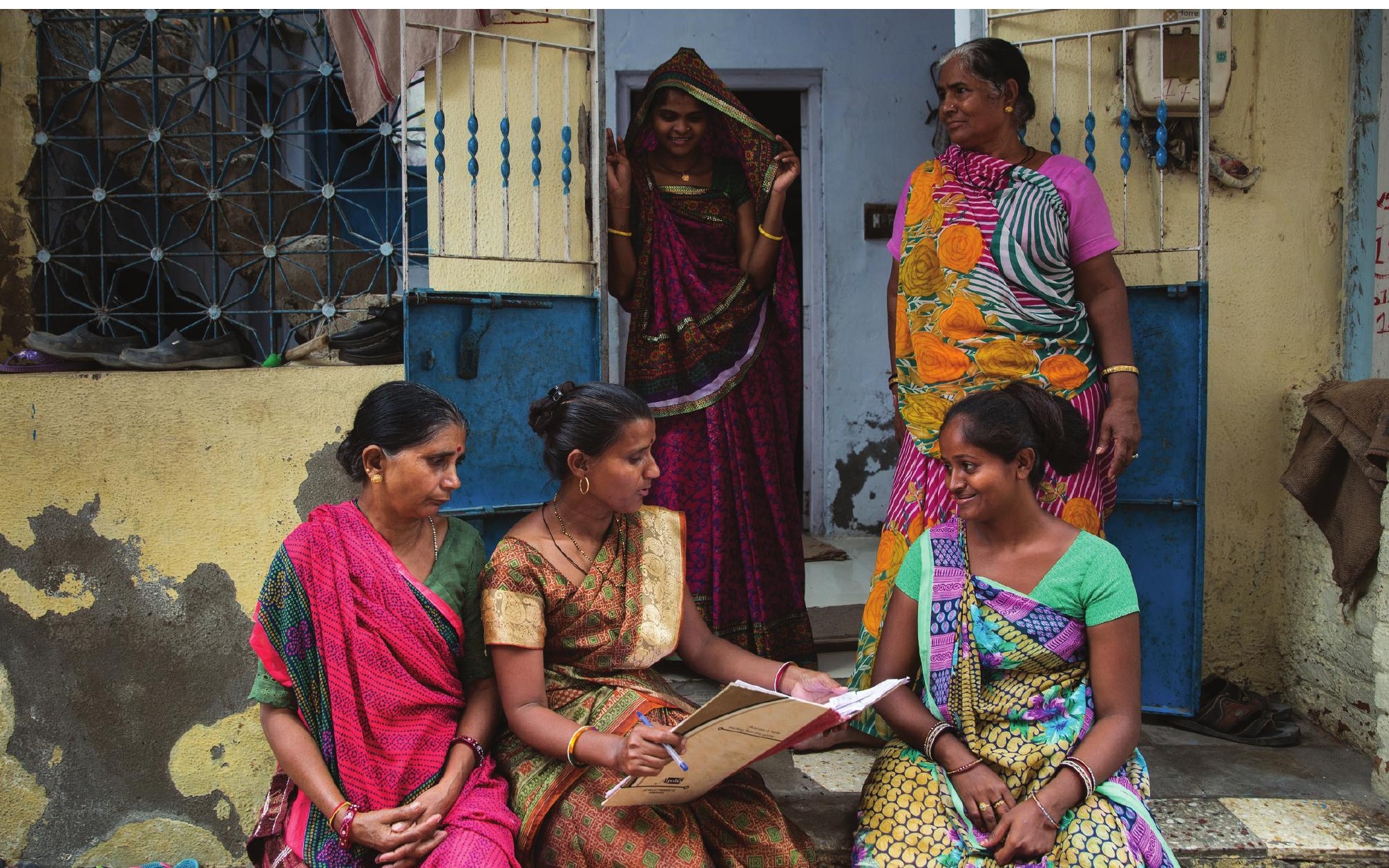




\section{Civil Society Involvement in Family Planning \\ A Review of Global Programming and Evidence}

Victoria Boydell, IPPF

Robin Keeley, PATH

Kumudha Aruldas, Population Council India

Karen Hardee, Population Council

DECEMBER 2017 
The Evidence Project is made possible by the generous support of the American people through the United States Agency for International Development (USAID) under the terms of cooperative agreement no. AID-OAA-A-13-00087. The contents of this document are the sole responsibility of the Evidence Project and Population Council and do not necessarily reflect the views of USAID or the United States Government.

\section{Evidence}

The Evidence Project uses implementation science-the strategic generation, translation, and use of evidence-to strengthen and scale up family planning and reproductive health programs to reduce unintended pregnancies worldwide. The Evidence Project is led by the Population Council in partnership with INDEPTH Network, International Planned Parenthood Federation, PATH, Population Reference Bureau, and a University Research Network.

Published in 2017.

Suggested citation: Boydell, Victoria, Robin Keeley, Kumudha Aruldas, and Karen Hardee. 2017. "Civil Society Involvement in Family Planning: A Review of Global Programming and Evidence," Working Paper. Washington, DC: Population Council, The Evidence Project.

Photo credit on cover page: Images of Empowerment

(c) 2017. The Population Council, Inc.

\section{Acknowledgments}

The authors would like to thank USAID/India for requesting this review of the literature, as it is an important and timely topic both for their purposes and for the general FP/RH community as more emphasis is put on the engagement of local civil society in the development and implementation of FP/RH programming. We hope that this review benefits the community more broadly and can be built upon as civil society continues engaging in programming and more of these programs are evaluated and published. We would also like to thank those organizations whose publications are included in this review for documenting their work and ensuring that it is in the public domain in order to share lessons learned. We would also like to thank colleagues who took the time to help review this document and provide very useful inputs, including Subrato Kumar Mondal, Monitoring, Evaluation and Learning (MEL) Advisor, USAID/India. 


\section{Table of Contents}

List of Acronyms .......................................................................

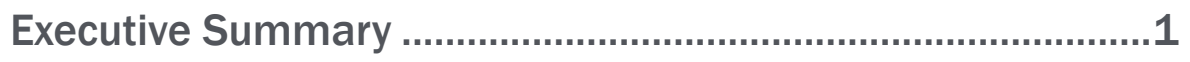

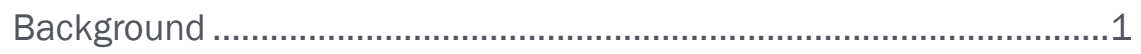

CSO Participation in FP/RH Programming .............................................1

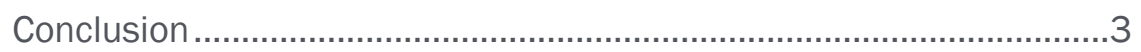

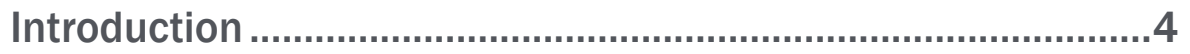

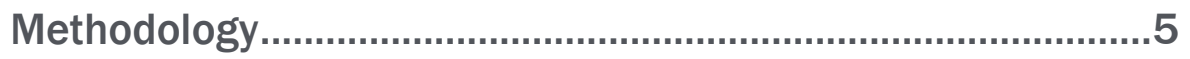

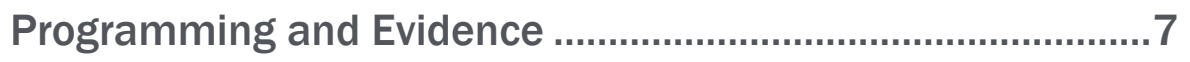

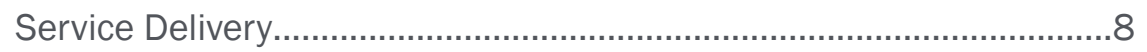

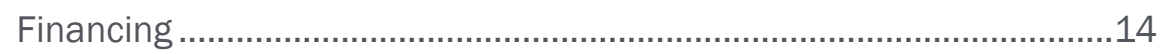

Social Franchising ...........................................................................16

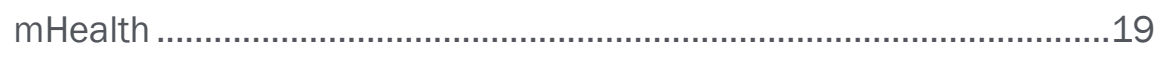

Human Rights and Quality of Care..................................................20

Introducing and Scaling Up Fertility Awareness Methods ....................22

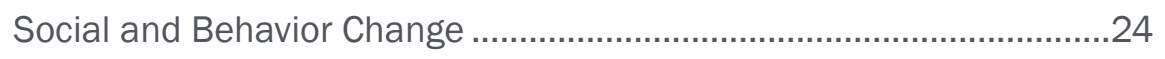

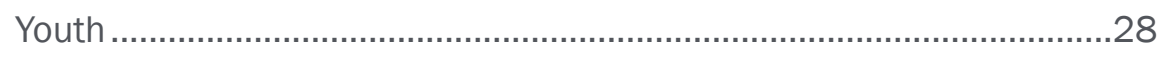

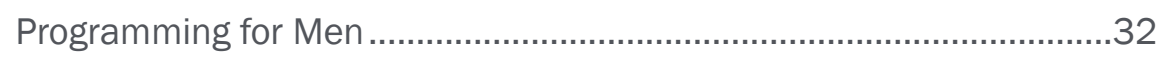

Advocacy/Accountability........................................................................33

Summary of Key Outcomes from CSO Engagement

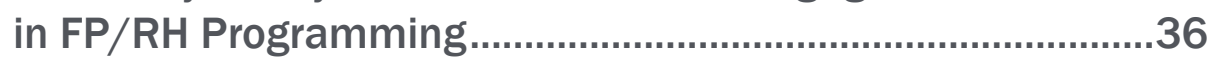

Evidence Gaps in CSO Programming for FP/RH ....................37

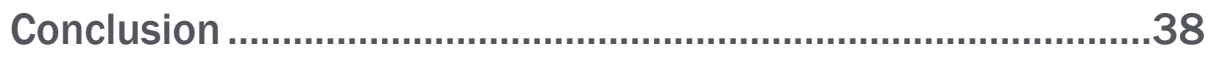

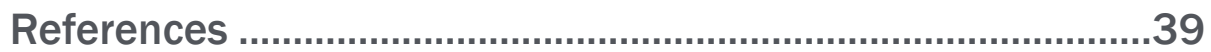




\section{List of Acronyms}

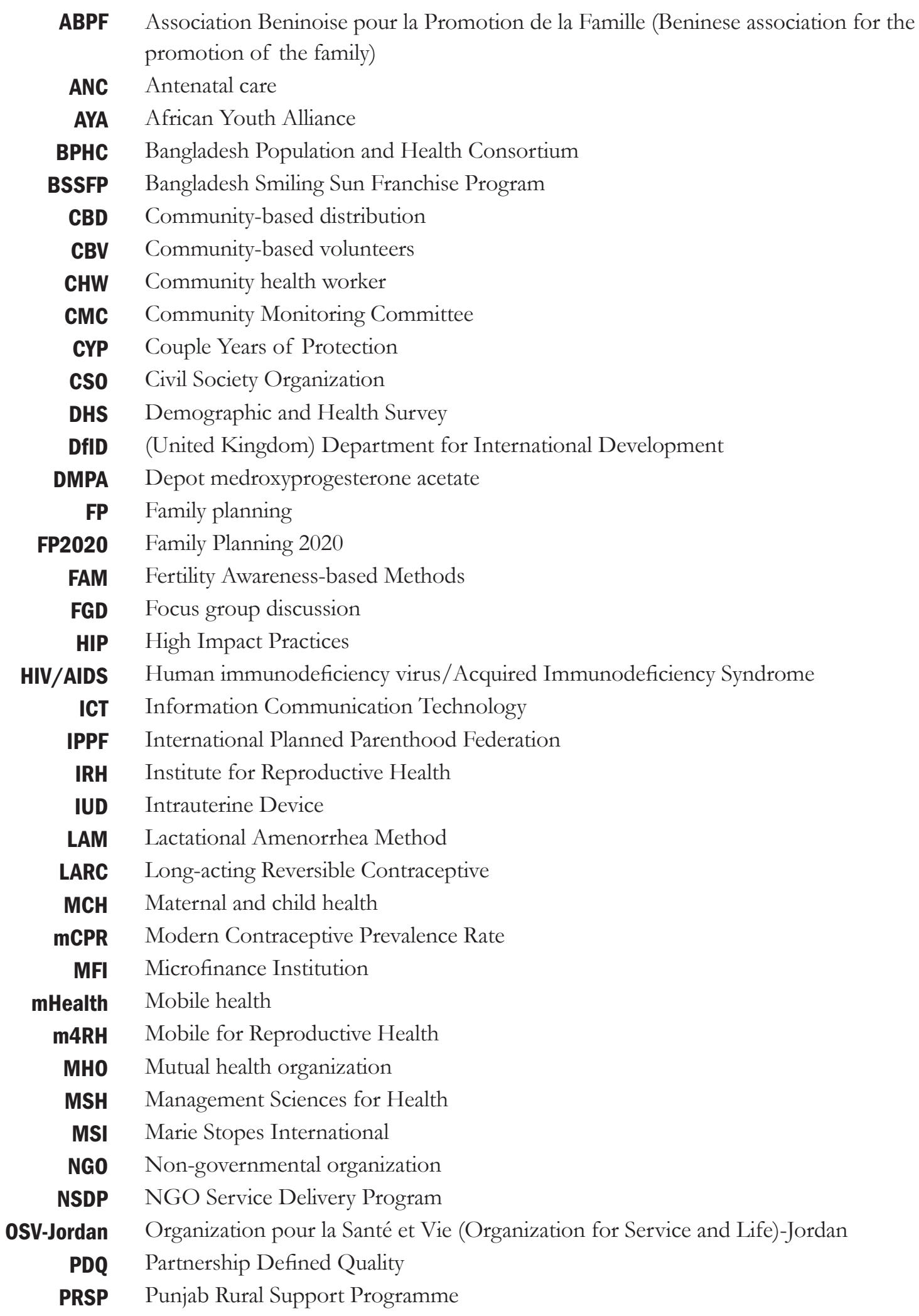


PSI Population Services International

RCH Repeoductive and Child Health

REACH Rural Expansion of Afghanistan's Community-based Healthcare

RH Reproductive Health

RTI Reproductive Tract Infection

SBC Social and behavioral change

SDM Standard Days Method

SHG Self-help group

SRH Sexual and Reproductive Health

USAID United States Agency for International Development

WHO World Health Organization

YMC Young Mothers Club 


\section{Executive Summary}

\section{Background}

Civil society plays an important role in the provision of high quality family planning programs. Civil society organizations (CSOs) are often involved in expanding services, raising awareness, generating demand, and advocating for an improved enabling environment to ensure women and men have full, free and informed choice to determine whether and when they have children. Despite being a valued partner in many programs, there is little evidence on the contribution that CSOs have made to family planning and reproductive health (FP/RH) programs in terms of the types of activities undertaken and the impact that they can have. This review summarizes the evidence on civil society's engagement in improving family planning programs and highlights the possible opportunities to further strengthen civil society engagement in family planning programs.

\section{CSO Participation in FP/RH Programming}

A literature review was conducted to document the range of ways in which CSOs have been involved in family planning programming and to assess the strength of the evidence related to interventions that included $\mathrm{CSO}$ participation. The literature review identified $63 \mathrm{FP} / \mathrm{RH}$ interventions described in 60 publications that involved civil society, either as a prime implementer or collaborator, and that had been evaluated. Many CSO activities and interventions are not documented or assessed, or are not publicly available, and therefore could not be included.

The interventions identified generally fell under the following 10 technical strategy areas: service delivery (facilitybased, community-based, and mobile outreach), financing, social franchising, mHealth, human rights and quality of care, introducing and scaling-up fertility awareness methods, social and behavior change (community and individual), youth (community-based, school-based, facility-based, and combination community/school/ facility), programming for men, advocacy/accountability (capacity building, and community-led assessment and monitoring). The interventions were spread across 27 countries spanning Africa, Asia, Latin America and the Caribbean, and Europe. Outcomes identified related to contraceptive use included increased uptake, changes in knowledge and information about modern contraceptives, other sexual or reproductive health behavior changes, and changes in intention to use contraception.

Given the wide range of interventions and evaluation methodologies drawn from peer reviewed and grey literature that cannot be compared to each other directly, the Grey Scale (Table 1, page 6) was used to determine the strength of the evidence and give an overall assessment to the interventions.

The strategies with the highest strength of evidence identified included CSO provision of facility-based family planning and social and behavior change (SBC) interventions. CSO provision of facility-based family planning had relatively strong evidence, with increases shown in the modern contraceptive prevalence rate $(\mathrm{mCPR})$ in both rural and urban settings. CSO-led SBC interventions were fairly strong and included the creation of local committees and self-help groups and work with local gatekeepers. Reported changes were seen in knowledge, attitudes and awareness about birth spacing and family planning, changes in behavior resulting in increased uptake of contraception, and/or changes in sexual behavior or contraceptive behavior, and increased capacity of service providers and of CSOs to undertake or support SBC communication.

Moderate evidence was seen in strategies including community-based service delivery, mobile outreach, financing, introducing or increasing access to fertility awareness methods, and programming for men. Community-based 
Intervention categories and number of interventions identified*

\begin{tabular}{|c|c|}
\hline Intervention Category & $\begin{array}{l}\text { Number of Interventions } \\
\text { Included in the Review }\end{array}$ \\
\hline \multicolumn{2}{|l|}{ Service Delivery } \\
\hline Facility-Based & 7 \\
\hline Community-Based & 3 \\
\hline Mobile Outreach & 3 \\
\hline Financing & 4 \\
\hline Social Franchising & 8 \\
\hline mHealth & 2 \\
\hline Human Rights and Quality of Care & 4 \\
\hline $\begin{array}{l}\text { Introducing and Scaling Up Fertility Awareness } \\
\text { Methods }\end{array}$ & 5 \\
\hline \multicolumn{2}{|l|}{ Social and Behavior Change } \\
\hline Community & 6 \\
\hline Individual & 2 \\
\hline \multicolumn{2}{|l|}{ Youth } \\
\hline Community-Based & 4 \\
\hline School-Based & 1 \\
\hline Facility-Based & 2 \\
\hline Combination of Community/School/Facility & 5 \\
\hline Programming for Men & 2 \\
\hline \multicolumn{2}{|l|}{ Advocacy/Accountability } \\
\hline Capacity Building & 1 \\
\hline Community-Led Assessment and Monitoring & 4 \\
\hline Total & 63 \\
\hline
\end{tabular}

* Multi-component interventions are only counted once in this table, under the primary technical strategy.

service delivery interventions had modest evidence, with much of it drawn from feasibility and operations research. CSO involvement in mobile outreach has the potential to be an effective way to deliver family planning methods to increase client satisfaction and deliver a wider range of methods, particularly increasing access to IUDs and implants. CSO involvement in financing interventions also has modest evidence, with mixed results. The most notable results were a modest increase in knowledge and awareness of contraception.

The findings related to CSO involvement in social franchising are mixed, with general increases in awareness and knowledge of contraception, but inconsistent data on the impact on contraceptive uptake and use. There were also mixed findings on the effect of CSO social franchising on equitable access, though demand-side vouchers appeared to be affordable and acceptable for family planning users.

The strength of the findings about CSOs introducing or increasing access to fertility awareness contraceptive methods is moderate, but suggests these interventions increased knowledge about the methods, increased use of the methods, and increased acceptability among clinic-based and community-based providers.

CSO involvement in programming for increased male participation in FP/RH programs is also moderate. The programs were mainly focused on increasing men's sense of responsibility for and access to contraception, and promoted positive changes in men's attitudes and support for family planning. 
The findings for CSO interventions that employed mHealth are drawn from operational research rather than rigorous evaluations. Nevertheless, findings suggest that $\mathrm{mHealth}$ services designed to respond to queries about contraceptive methods were popular and may have helped users find the best method for them.

The strength of evidence about CSOs implementing family planning using rights-based approaches is low, although with generally positive reporting from clients related to better treatment, greater confidence asking questions, and better counselling.

Adolescent-friendly contraceptive programs provided at the community, school, and facility levels, and as part of larger interventions saw mixed results. Better results were seen for interventions that focused on reaching individuals and for interventions that combined service provision and education.

Most of the advocacy and accountability interventions identified focused on building the capacity of CSOs and facilitating interventions related to community engagement and participation. The evidence to support these types of interventions was generally weaker and tended to focus on process outcomes such as capacity building and positive statements made in favor of family planning.

\section{Conclusion}

The results from this literature review indicate that CSOs have a unique and significant role to play in family planning programs and have a great potential to aid in piloting innovations and scaling up proven programs. CSO interventions related to service delivery, adolescent programming, and social and behavior change showed significant contributions to improving access to family planning programs, leading to increased knowledge and awareness, contraceptive use and client satisfaction. Moreover, the examples from other technical areas captured in this review show the role CSOs have played in testing new ways of programming to advance the provision of full, free and informed choice. Many of the interventions that included a strong contribution from civil society were multi-stakeholder initiatives with limited description of the specific inputs of each stakeholder, making it challenging to determine the exact role and contribution of individual stakeholders, including civil society. 


\section{Introduction}

With an ambitious FP2020 goal of providing access to high quality and rights based FP services for an additional 120 million women and girls, multi-sector coordination is even more important to maximize the contributions at the global and country levels. In line with the total market approach, this means that governments, the commercial private sector, and civil society all need to participate and bring their strengths to country level FP programs.

The start of the Sustainable Development Goals and the recently-passed mid-point of the FP2020 initiative have reinforced global focus on how countries can maximize the money spent on improving FP information and/or services and achieve ambitious global commitments to reach an increased number of women with an unmet need for FP. There is great potential in maximizing the role that civil society organizations can play in the provision of high quality family planning programming. Civil society organizations work to expand services, raise awareness, generate demand, offer training, and advocate for an improved enabling environment to ensure that women and men are able to enjoy full, free and informed choice about whether and when to have children. Despite being a valued partner in many programs, little is known about the contribution that CSOs make to $\mathrm{FP} / \mathrm{RH}$ programs in terms of the types of activities undertaken and the impact that they can have on access to and use of contraception information and/or services.

Given the recognition of the important role that civil society can play in contributing to sustainable FP/RH programming at the country level, this literature review highlights the areas in which civil society is already playing a role and the areas in which that role could be increased. ${ }^{1}$ This review will help governments and donors to program resources in ways that include civil society in a range of activities to promote and provide family planning. The review will also assist CSOs in developing programming, including to promote accountability for family planning.

1 This review was requested by USAID/India for India's Ministry of Health and Family Welfare. 


\section{Methodology}

An iterative literature search, described in more detail in Appendix 1, was undertaken to identify activities, interventions and research evidence on civil society engagement in family planning/reproductive health (FP/ $\mathrm{RH}$ ) interventions globally, with a focus on those in Asia, and to highlight the FP/RH-related outcomes to help government program managers to more effectively incorporate civil society into FP/RH programs.

This review defined civil society organizations (hereafter referred to as CSOs) as the organizations and institutions that represent the interests and will of citizens distinct and independent from government and private sector business (Johns Hopkins University Institute for Policy Studies 2004). These may include grassroots/community-based organizations, national coalitions, national and state level non-governmental organizations (NGOs), national and state level CSOs, professional associations, faith-based organizations, unions, media and corporate social responsibility units of companies. Interventions with international NGOs were only included if they worked with a national or local CSO. Exceptions were made for organizations like Marie Stopes International and Population Services International that had a country presence in addition to an international presence.

Searches of PubMed and POPLINE for English language publications for the years 1995-2015 and for lowand middle-income countries yielded 8,094 references. These materials spanned the years 1980 to 2016. The articles and reports included those that reported on an evaluation or study of an FP/RH intervention, were designed and/or implemented by one or more CSOs, reported some level of impact on access to and use of contraceptive information and/or services. The studies reported outcomes of interest related to contraceptive uptake and use. This includes outcomes such as contraceptive uptake, change in knowledge and information of modern contraceptives, behaviour change, or change in intention to use contraception. Studies were excluded if they are not relevant to CSO designed and/or implemented interventions that improve access and/or use of contraceptives.

Based on these criteria, 4,644 abstracts were reviewed. From these, 60 publications that covered 63 interventions met the full criteria for inclusion. A data extraction form was designed for the publications undergoing detailed review. The extraction form captured pertinent information about the type and role of the CSO, location, target population, type of intervention, outcomes, and type and quality of the study. The selected publications were then grouped according to intervention type by the authors and assessed in groupings and compared across categories. The interventions found were then grouped into broader strategy categories. Strategy categories were developed iteratively, first by listing the most common FP interventiona areas, and then refining them after the review of the identified interventions. Many effective interventions occur without the ability to conduct rigorous research and/or publish their findings. To ensure learning from the full range of interventions being implemented was captured, the literature search extended beyond peer reviewed journals to include grey literature which described a less rigorous study or evaluation, and documents reporting service statistics, provided they met the inclusion criteria.

Grading the strength of this range of evidence, however, with traditional grading structures presents a challenge. To address this, the modified Grey Scale was used determine the strength of the evidence supporting the interventions. Described in www.whatworksforwomen.org, the modified Grey Scale attaches to studies one of six levels of evidence. Used with geographic spread of the evidence, this methodology shows the strength of evidence associated with interventions. Table 1 shows the definitions of levels I through $\mathrm{V}$ on the modified Grey Scale. 
TABLE 1

Modified Grey Scale of the Strength of Evidence

\begin{tabular}{|c|c|}
\hline Type & Strength of Evidence \\
\hline I & $\begin{array}{l}\text { Strong evidence from at least one systematic review of multiple well designed, randomized } \\
\text { controlled trials. }\end{array}$ \\
\hline II & $\begin{array}{l}\text { Strong evidence from at least one properly designed, randomized controlled trial of } \\
\text { appropriate size. }\end{array}$ \\
\hline IIIa & $\begin{array}{l}\text { Evidence from well-designed trials/studies without randomization that include a control } \\
\text { group (e.g. quasi-experimental, matched case-control studies, pre-post with control group) }\end{array}$ \\
\hline IIIb & $\begin{array}{l}\text { Evidence from well-designed trials/studies without randomization that do not include a } \\
\text { control group (e.g. single group pre-post, cohort, time series/interrupted time series) }\end{array}$ \\
\hline IV & $\begin{array}{l}\text { Evidence from well-designed, non-experimental studies from more than one center or } \\
\text { research group. }\end{array}$ \\
\hline V & $\begin{array}{l}\text { Opinions of respected authorities, based on clinical evidence, descriptive studies or reports } \\
\text { of expert committees. }\end{array}$ \\
\hline
\end{tabular}

http://www.whatworksforwomen.org/pages/methodology; accessed February 27, 2017

There are some limitations to this literature review. First, it was difficult to directly compare the peer-reviewed and grey literature, which are presented in different ways and have different standards of rigor. Second, the grey literature does not capture the range of activities undertaken by CSOs (particularly advocacy work) nor does it always present the intervention in a clear manner. Third, many of the interventions identified were complex, with multiple components and/or several stakeholders involved in the design and implementation, often without clear explanation of which organizations were involved in what aspects of the interventions and to what extent, making it difficult to decipher the exact contribution and role of the $\mathrm{CSO}(\mathrm{s})$. Fourth, there may be a bias towards interventions with significant investment in monitoring, evaluation, and research that allowed for more robust studies or program data, and that may therefore have been more likely to publish in the peerreviewed and grey literature. Smaller interventions or organizations may not have the resources to monitor and document their work in the same way as a larger, donor-supported project. This could also have biased the types of programs identified in favor of those that fell into donors' priority areas. Finally, it is possible that some articles or reports were missed in the literature search. However, we believe that most recent interventions were captured by this review. 


\section{Programming and Evidence}

The review came to a final list of 63 interventions that encompassed ten strategies. The main strategies identified include: 1) service delivery (facility, community-based, and mobile outreach), 2) financing, 3) social franchising, 4) mHealth, 5) human rights and quality of care, 6) introducing and scaling up fertility awareness methods, 7) social and behavior change, 8) youth, 9) programming for men, and 10) accountability/empowerment. A small number of interventions were identified that used other strategies, such as population, health and environment, but few enough that they were removed to focus on the strategies with more interventions identified. Other strategies, such as social marketing, were removed because they are already categorized as proven practices by the USAID High Impact Practices Initiative. Many interventions were multifaceted, often using several of these intervention strategies together; they are discussed in the section to which the intervention was primarily relevant.

The interventions identified took place in four regions across the world, covering 27 countries in total, as shown in Map 1. This review includes interventions from 17 countries in sub-Saharan Africa (Tanzania, Madagascar, Ethiopia, Malawi, Uganda, Nigeria, Kenya, Senegal, Mali, Zambia, Zimbabwe, Sierra Leone, Benin, Burkina Faso, Ghana, Botswana, Togo), 7 countries in Asia (India, Bangladesh, Pakistan, Philippines, Vietnam, Nepal, and Myanmar), 2 countries in South America (Nicaragua and El Salvador), and 1 country in Europe (Republic of Georgia). Sixteen of the 63 interventions in this review were implemented in India.

\section{MAP 1}

Intervention locations

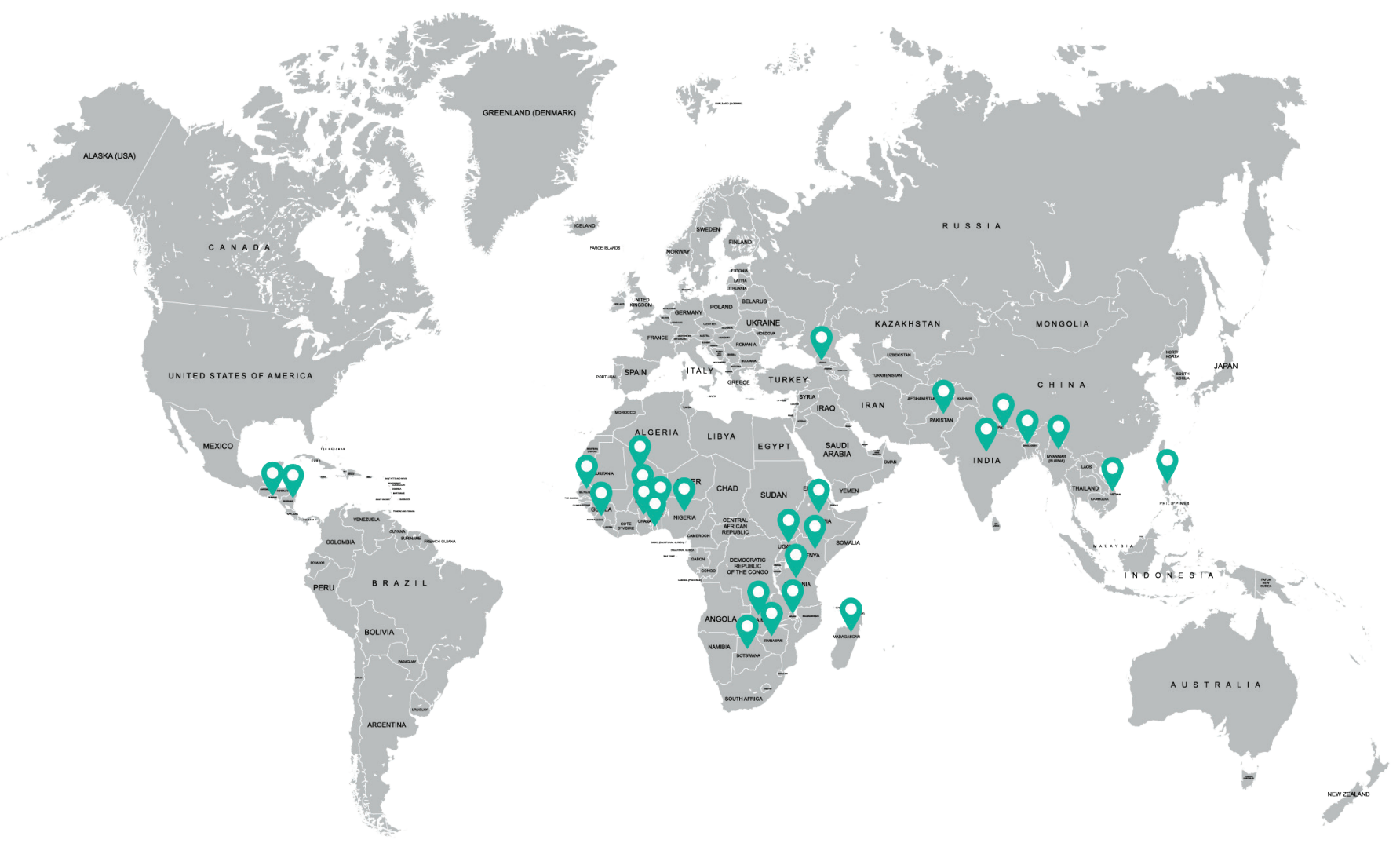


Appendix 2 contains more detail about each of the 63 interventions, including the outcomes associated with each.

For each strategy, the range of evidence supporting the interventions is described, along with the countries in which the interventions have been implemented. This gives a sense of the geographic spread of experience implementing the strategies.

Given the diversity of interventions and evaluations included under each strategy and varying strengths of evidence, it is challenging to give an overall strength to each strategy. Using the Grey Scale (Table 1), each study/evaluation of an intervention within each of the 10 strategies is given a Grey level rating (I-V) and the summary of the supporting evidence is taken into account when discussing CSO participation in interventions in that strategy.

\section{Service Delivery}

The review found that civil society organizations have been involved in implementing three types of service delivery interventions: facility-based, community-based, and mobile outreach.

\section{Facility-Based Service Delivery}

Facility-based family planning service delivery is the most common form of service provision. Traditionally, facility-based service provision includes doctors, nurses, and midwives, though it is growing to include more provider types, such as pharmacists, drug shop owners, and auxiliary health staff. Facility-based service delivery is a multi-sectoral approach that can involve provision of services through the total market, including the public health system, NGO clinics, and the for-profit private sector.

\section{TABLE 2}

Facility-Based Service Delivery

\begin{tabular}{|c|c|}
\hline Intervention/evaluation & $\begin{array}{l}\text { Grey Scale } \\
\quad \text { level }\end{array}$ \\
\hline Increasing Use of FP and Other Services, Bangladesh & IIIA \\
\hline Delivering FP-MCH Services to Poor and Underserved Communities, Bangladesh & IIIA \\
\hline Improving Rural SRH, Bangladesh & IIIA \\
\hline Improving Urban SRH, Bangladesh & IIIA \\
\hline Increasing Use of FP/RH Services at the Facility and Community Level, Uganda & IIIB \\
\hline Mobilizing Faith-based Networks to Promote and Deliver FP Services, Ethiopia & IV \\
\hline $\begin{array}{l}\text { Expanding Contraceptive Choice Through Capacity Building of NGOs: West Africa (Benin, } \\
\text { Burkina Faso, Togo) }\end{array}$ & IV \\
\hline * Improving Youth SRH in India (see section on Youth strategy) & IIIA \\
\hline $\begin{array}{l}\text { * Quality FP and RTI Services for Urban Slum Populations, Bangladesh (see section on } \\
\text { Human Rights and Quality of Care strategy) }\end{array}$ & IIIB \\
\hline $\begin{array}{l}\text { Strengthening Delivery of Quality RH Services to Women } \text { and Couples from Disadvantaged } \\
\text { Groups, Nepal (see section on Human Rights and Quality of Care strategy) }\end{array}$ & IIIB \\
\hline $\begin{array}{l}\text { * Sustaining FP Practices Among Marginalized Groups, Nepal (see section on Human Rights } \\
\text { and Quality of Care strategy) }\end{array}$ & IIIB \\
\hline
\end{tabular}

*Indicates an intervention that is cross-referenced with another strategy. These interventions are described in the section on the primary strategy they apply, shown in parenthesis. 
Countries: The review found 11 facility-based service delivery interventions implemented by civil society organizations. Four of these were multi-component interventions that included a facility-based platform but fell primarily under a different technical strategy (marked by an asterisk); these are described in the section on their respective primary strategy. The 11 interventions took place in eight countries, largely in the Asia region (Bangladesh, India, and Nepal) but also in sub-Saharan Africa (Benin, Burkina Faso, Togo, Ethiopia, and Uganda).

Supporting Evidence: The evidence for facility-based service delivery was relatively strong, with five of the studies/evaluations scoring IIIA on the Grey Scale, indicating that they were non-randomized studies that included control groups. Four of the studies/evaluations did not include control groups and thus were rated IIIB, while the other two were non-experimental studies and thus were rated IV.

Interventions and Outcomes: The facility-based service delivery interventions identified were varied, but generally focused on increased use and/or quality of services, usually through increasing the technical and/or operational capacity of CSO clinics to provide FP/RH services.

To increase use of family planning and other services in Bangladesh, the Bangladesh Smiling Sun Franchise Program (BSSFP) was designed and implemented by Chemonics, with funding from USAID, through 26 local NGOs that operated a network of 323 static clinics and more than 8,000 satellite clinics (Lance, Angeles, and Kamal 2012). The mCPR increased in rural intervention areas by two percentage points (50\% to $52 \%$ ), while in comparison areas the increase was similar (49\% to 52\%). These increases brought the mCPR in these areas to similar levels as those seen in areas served by the government, despite the fact that BSSFP did not have the strong door-step delivery or free services like the public sector. In urban areas, though overall contraceptive use increased, modern method use decreased in both intervention areas (50\% to 57\%) and control areas. BSSFP's market share of FP services declined from 35\% to 30\% (p value <.05) in rural areas and from 19\% to 18\% (not statistically significant) in urban areas, while the market share of users in the public sector rose from $24.5 \%$ to 31\%, with more women using public sector services in BSSFP project areas in 2011 than in 2008.

The DFID-supported Bangladesh Public-NGO Partnership project, implemented by the Bangladesh Population and Health Consortium (BPHC), provided financial and technical support to 36 local NGOs delivering the government's Essential Services Package to deliver FP-MCH services to poor and underserved communities (MEASURE Evaluation and ACPR 2005). Except for the home delivery of family planning services, BPHC's service delivery model was similar to that of the USAID-funded Urban and Rural NGO Service Delivery Program (NSDP). The NSDP and BPHC programs were evaluated concurrently in 2003, with the same design, instruments, and sampling procedures used for both interventions, allowing for comparability. The BPHC design was intended to look at two sample domains: BPHC project areas not adjacent to NSDP areas and BPHC project areas adjacent to rural NSDP areas. Generally, health and utilization indicators were slightly better in BPHC areas. In some areas, adjacent to the urban and rural NSDP areas, BPHC indicators tended to be slightly better (e.g. the CPR was 56\% in the full BPHC sample, $56 \%$ in the BPHC-adjacent areas, $54 \%$ in rural NSDP, and 53\% in NSDP-adjacent areas). The poorest women were found to be less likely to use modern contraceptives, but those that did tended to go to a BPHC provider $(22 \%)$ instead of a public provider $(11 \%)$ or a pharmacy $(3 \%)$. Among all wealth quintiles, BPHC facilities were also the most common source for modern contraceptives.

The USAID-funded Urban and Rural NGO Service Delivery Programs (NSDP) in Bangladesh were similar to the BPHC program, and delivered the government of Bangladesh's Essential Services Package. Mid-term evaluations of the Urban and Rural NSDP programs were done in 2001 and 2003, and then endline evaluations 
were done in 2005. The Rural NSDP program worked through 41 local NGOs to improve rural SRH in Bangladesh, and the evaluation compared rural intervention areas and adjacent rural non-intervention areas (MEASURE Evaluation and ACPR 2006). There was a consistent upward trend in modern contraceptive prevalence among currently married women in NSDP areas, which increased by four percentage points (46\% to $50.2 \%$ ) from 2003 to 2005. Oral contraceptive use increased from $23 \%$ in 2003 to $25 \%$ in 2005 and injectables increased from almost $14 \%$ to almost $16 \%$ during the same period. There was a smaller modern contraceptive use increase in comparison areas, with just over a 2 percentage point increase. There was some difference in use of modern contraception among married adolescents in NDSP and non-NDSP areas, with use higher among married adolescents in project areas than in non-project areas: among 10-14 year olds, $27 \%$ used modern contraception in project areas versus $16 \%$ in non-project areas, while $40 \%$ of $15-19$ year olds in project areas used modern contraception versus 34\% in non-project areas. NSDP NGO clinics were the main source of contraceptives for the Rural NSDP project area, while the public sector was the primary source in non-project areas. Of the women in NSDP areas using NSDP clinics, 50\% were from the poorest two quintiles.

The Urban NGO Service Delivery Program (NSDP) was the urban counterpart to the Rural NSDP program and worked in collaboration with 17 NGOs to improve urban SRH in Bangladesh (MEASURE Evaluation and Mitra and Associates 2006). Similarly to the Rural NSDP program, 2001 and 2003 mid-term evaluations and a 2005 endline evaluation compared project and non-project areas. Modern contraceptive prevalence was approximately $57 \%$ in both NSDP and non-NSDP areas. Overall contraceptive prevalence in NSDP areas increased by 4 percentage points between 2003 and 2005, and use of modern methods increased by the same amount. In non-NSDP areas, contraceptive prevalence increased by only 2 percentage points. Married adolescent contraceptive use was more mixed in the urban areas. Forty-eight percent of 10-14 year olds were using a modern method in NSDP areas, compared to 54\% in non-NSDP areas. Among 15-19 year olds, 51\% in NSDP areas were using a modern method, compared to $48 \%$ in non-NSDP areas. NSDP clinics are the third most popular source for modern contraceptives in NSDP project areas, used by $16 \%$ of modern contraceptive users, following the private medical sector (55\%), and the public sector $(19 \%)$. The largest percentage of women from the poorest two wealth quintiles went to the private medical sector for their modern contraceptives in NSDP project areas, followed by the public sector and then NSDP NGOs.

In Uganda, the STRIDES for Family Health intervention aimed to increase the use of FP/RH services at the facility and community levels in Uganda (Makerere University DSWSA 2015). The STRIDES project, funded by USAID, was implemented by an international NGO (Management Sciences for Health (MSH)) in collaboration with local NGOs. The project worked to strengthen various health system components, but also worked on performance-based financing with NGOs to help expand access to services and to improve youth uptake of FP/RH services. The evaluation of STRIDES found that modest success was seen in relation to the health systems strengthening goal. By the end of the project, the percentage of facilities that complied with national infrastructure standards increased from $48 \%$ to almost $70 \%$. This includes infrastructure improvements by the project as well as through other agencies or initiatives. The project also contributed to stabilization of family planning supplies through a stock-out monitoring system and a plan for internal redistribution, which is thought to have contributed to a 5\% increase in new FP users and 38\% in repeat users between years 4 and 5 of the project. By project year 5 , there were 503 service delivery points offering FP counseling or related services, exceeding the end of project target by $98 \%$. Almost $97 \%$ of facilities were offering at least one modern contraceptive method, exceeding the end of project target by more than $5 \%$. The goal for service delivery points offering long acting methods was $60 \%$, but this was exceeded by 14 percentage points by the end of the project. The goal of $50 \%$ of service delivery points offering permanent methods was not reached, with only $25 \%$ of service delivery points offering these services. As part of the performance-based contracting activity, contractors said that their capacities were strengthened, which led to 
improved service delivery and increased client volume. Finally, despite inputs of health workers trained in youth friendly services and the creation of youth friendly corners/spaces, there was no evidence of increased demand for RH/FP services by young people in the facilities.

In Ethiopia, the USAID-funded Evidence to Action project provided grants and technical support to a faith-based organization, the Ethiopian Evangelical Church Mekane Yesus Development and Social Services Commission (EECMY-DASSC), to mobilize faith-based networks to promote and deliver FP services (Evidence to Action 2015). Community mobilization efforts through religious and kebele leaders and health extension workers led to more than 15,000 women newly adopting family planning in one year. Of the new acceptors, $48 \%$ were women between the ages of $15-24$. There was a significant increase in the number of women adopting IUDs, after 15 health facilities participated in clinical training with EECMY-DASSC.

To expand contraceptive choice through capacity building of NGOs in West Africa, the USAID-funded RESPOND Project, implemented by EngenderHealth and partners, provided technical assistance and small grants to International Planned Parenthood Federation (IPPF) clinics in West Africa (Benin, Burkina Faso, and Togo) (The RESPOND Project 2013). In Benin, the IPPF affiliate reported that couple years of protection (CYPs) from pills, injectables, implants, and IUDs increased by $24 \%$ over one year, from 35,017 in 2011 to 43,249 in 2012. Over the same time period, CYPs from these methods increased by $72 \%$ in Burkina Faso $(11,699$ to 20,077$)$ and by $83 \%$ in Togo $(9,770$ to 17,847$)$.

Overall, there is relatively strong evidence for the effectiveness of CSO provision of facility-based family planning, with increases in mCPR in both rural and urban settings.

\section{Community-Based Service Delivery}

Community-based service delivery interventions bring family planning information and services to the communities where people live. Increasing access through community-based distributors and community health workers is particularly relevant for people living in remote and hard-to-reach areas or areas where there are geographic, economic, or social restrictions that limit women's and men's access to reproductive healthcare.

Countries: The review identified four interventions that met the inclusion criteria, including three that were implemented in Asia (two in Bangladesh and one in India) and one in Africa (Madagascar).

\section{TABLE 3}

Community-Based Service Delivery

\begin{tabular}{|c|c|}
\hline Intervention/evaluation & $\begin{array}{l}\text { Grey Scale } \\
\text { level }\end{array}$ \\
\hline Improving Access for the Poor, Bangladesh & IIIA \\
\hline Expanding Community Provision of Injectable Contraception, Madagascar & IIIB \\
\hline Impact of Dropout of Female Volunteer Community Health Workers, Bangladesh & IV \\
\hline $\begin{array}{l}\text { * Increasing Use of LAM in India (see section on Introducing and Scaling Up Fertility } \\
\text { Awareness Methods) }\end{array}$ & IV \\
\hline
\end{tabular}

*Indicates an intervention that is cross-referenced with another strategy. These interventions are described in the section on the primary strategy they apply, shown in parenthesis. 
Supporting Evidence: The evidence supporting these interventions was modest, with one evaluation based on a project-specific, pre- and post-test with comparison sites design (Grey Scale IIIA), one based on a survey of users (Grey Scale IIIB), one qualitative study, and one cost evaluation, both Grey Scale IV.

Interventions and Outcomes: The review of CSO provision of community-based family planning found two types of interventions. The first type was building the capacity of community-level health workers (depotholders, community health workers, or community-based distributors). The second type focused on expanding the range of contraceptive methods provided by community health workers, specifically injectables. Most of the interventions were multi-component interventions, also including strategies such as training lower cadre health workers and undertaking information and education campaigns to increase the acceptability of contraception.

The NGO Service Delivery Program, led by Pathfinder International, which provided support and technical assistance to 33 local NGOs in Bangladesh, sought to improve access for the poor to the government's Essential Services Package through improved community-based access by introducing depot-holders in three urban areas (Gazi et al 2005). Depot-holders are women from the community who stocked commodities (such as contraceptive pills, condoms, and oral rehydration salts) in their homes to provide to fellow community members, and promoted good health practices and use of clinics. Service statistics from the depot-holder pilot intervention showed mixed results, but an overall increase in the quantity of commodities supplied by the depot-holders and NGO clinics. In Sherpur, condom distribution increased by more than 16,000 units (103\% increase) and pill cycle distribution increased by close to 7,000 (45\% increase); in Brahmanbaria, condom distribution declined by almost 8,000 units (35\% decrease) but pill cycle distribution increased by almost 5,000 (42\%); and in Dhaka, condom distribution increased by more than 1,200 units (5\% increase) and pill cycle distribution increased by almost 2,000 ( $54 \%$ increase). There was also an overall increase from the preintervention to intervention year in the average number of client contacts per month for FP (an increase of $26 \%$ in Sherpur, $55 \%$ in Brahmanbaria, and $76 \%$ in Dhaka).

In Madagascar, the Ministry of Health and Family Planning collaborated with the international NGO FHI 360 on an intervention to test whether community-based distribution (CBD) workers could be successfully trained to expand community provision of injectable contraception (Hoke et al 2011). In the selected regions, CBD services were supported by local and international NGOs. The results showed that of the 1,662 women adopting DMPA, 41\% were new or re-starting contraceptive users and, of the 924 women eligible for a second shot, $93 \%$ received one, with $96 \%$ of those returning to the CBD worker and the rest going to a facility. To assess geographic accessibility, women seeking services were asked about average travel time to the CBD's home (27 minutes) and the nearest health facility (136 minutes). CBD workers were enthusiastic about providing DMPA and $96 \%$ of interviewed clients said they were very satisfied with DMPA as a method and 92\% said they would recommend that a friend obtain DMPA services from the CBD worker.

In Bangladesh, BRAC, a large national NGO, used a large cadre of community health workers (CHW) to provide RH and other services, in part through the Manoshi intervention operating in the urban slums of Dhaka (Alam et al 2012). The slums experienced high CHW dropout rates, and this study examined the impact of dropout female volunteer CHWs from the intervention on BRAC and the community. When a CHW dropped out, a new CHW had to be recruited on an ad hoc basis (rather than through the regular recruitment process). Ad-hoc CHWs carried slightly higher costs (associated with recruitment, training, monitoring, and so forth) than CHWs recruited through the regular process ( $\$ 60.04$ vs $\$ 59.28$, respectively). There was also an impact on the community, since they do not have health services while the ad hoc CHW is recruited and trained. The cost of CHW incentives (about $\$ 121$ per year per $\mathrm{CHW}$ ) would save both the additional cost of recruiting and training ad hoc CHWs ( $\$ 60$ per CHW) as well as the cost of lost services to the community. 
Overall, there is modest evidence on CSO community-based service delivery interventions, with much of the existing evidence drawn from research on feasibility and operations.

\section{Mobile Outreach}

Another element of community-based service provision is using mobile outreach services to bring family planning information and methods to communities with high unmet need for family planning and limited access to contraceptives. Providing services directly in communities can help address inequities in access to family planning services. Outreach models equip health care providers with family planning commodities, supplies, equipment, and vehicles and send them to provide specialist services in areas with the greatest need at specified intervals.

\section{TABLE 4}

Mobile Outreach

\begin{tabular}{|c|c|}
\hline Intervention/evaluation & $\begin{array}{l}\text { Grey Scale } \\
\text { level }\end{array}$ \\
\hline Increasing IUD Use in Hard to Reach Areas, Pakistan & IIIB \\
\hline $\begin{array}{l}\text { Improving Mobile Outreach Service Quality, (Ethiopia, Myanmar, Pakistan, Sierra Leone, } \\
\text { Vietnam) }\end{array}$ & IV \\
\hline Scaling up Delivery of Contraceptive Implants in sub-Saharan Africa (15 countries) & IV \\
\hline
\end{tabular}

Countries: The review includes three interventions that used mobile outreach to send specialist teams to provide family planning information and methods directly to communities. These interventions were in Ethiopia, Myanmar, Pakistan, Sierra Leone, Vietnam, and 15 countries in sub-Saharan Africa.

Supporting Evidence: The evidence supporting these interventions are drawn from one non-randomized experimental study without a control group (Grey Scale IIIB), non-experimental studies in five countries (Grey Scale IV), and one non-randomized study with no control group using service statistics from interventions in 15 countries (Grey Scale IV).

Interventions and Outcomes: The mobile outreach model brings together health care providers, family planning commodities, supplies, equipment, and vehicles that are then directly sent to provide specialist services to areas with the greatest need over a set of specified intervals. The aim is to reach communities with high unmet need for family planning and limited access to contraceptives and address inequities in access to family planning services. In addition, the specialist teams are trained to provide more complex family planning methods, such as implants and IUDs (insertion and removal), which can help expand the method mix and choice available for underserved clients.

In Pakistan, the Marie Stopes Society, a Global Partner of Marie Stopes International, established mobile outreach services to increase access to IUDs in hard to reach areas and improve access to quality contraceptive services (Azmat et al 2013a). Of the women participating in the intervention who decided to use an IUD, 53\% had not previously used any form of contraception, while almost $41 \%$ switched from a shortterm method. At a 10-month follow up interview, 19\% had discontinued, mostly due to side effects (69\%) including bleeding (45.2\%) and pain and other side effects (12.1\%). Of those who discontinued, almost 57\% did not switch to another method and 30\% switched to a short-term method. Out of all women, $85 \%$ of users reported being satisfied with the IUD insertion services, and 95\% said that they would recommend the IUD to friends and relatives. 
A 2010 evaluation of five MSI mobile outreach interventions focused on increasing provision of IUDs and implants and improving mobile outreach service quality in Ethiopia, Myanmar, Pakistan, Sierra Leone and Vietnam (Eva and Ngo 2010). Overall, among the 4,273 women who were recontacted (995 implant and 3,278 IUD users), client satisfaction was very high in all five countries (73\%-93\%) and at least 78\% in all five countries (nearing 100\% in some) said that they would recommend the service to a friend. The six-month prevalence of implant discontinuation was $0.7 \%$ in Ethiopia and 3\% in Sierra Leone, while the six-month prevalence of IUD discontinuation was 13\% in Sierra Leone, 10\% in Myanmar, 8\% in Pakistan, and 1\% in Vietnam. Side effects were the top reason (cited by $53 \%-81 \%$ of women) for discontinuation. Of those who had their IUD or implant removed but did not want to get pregnant, the majority either discontinued contraceptive use or switched to short-term methods (23\%-75\%); the exception was Vietnam, where $43 \%$ of women switched to fertility awareness methods. About $80 \%$ of women in Ethiopia, Sierra Leone, Myanmar, and Pakistan had little to no education; in Vietnam, $30 \%$ had primary education or less.

In 15 countries in sub-Saharan Africa, MSI implemented interventions to scale up delivery of contraceptive implants and increase voluntary access to implants through existing service delivery channels, including mobile outreach, social franchising, and clinics (Duvall et al. 2014). In 2012, mobile outreach services, in conjunction with free or subsidized services, accounted for $70 \%$ of implants delivered by MSI, with high levels of client satisfaction.

Overall findings suggest that mobile outreach has the potential to be an effective way to deliver family planning methods to increase client satisfaction and deliver a wider range of methods, particularly IUDs and implants.

\section{Financing}

Financing is a USAID high impact practice to improve the enabling environment for FP/RH commodities and services. It encompasses a wide range of supply and demand side interventions, including use of vouchers, insurance, results-based financing or performance-based incentives, financing for commodities, and contracting to the private sector, among others (High-Impact Practices in Family Planning, 2014). These are all interventions that can help to decrease the out of pocket expenditures to the client, which could limit access to FP/RH services or the selection of the FP method of their choice.

\section{TABLE 5}

Financing

\begin{tabular}{|c|c|}
\hline Intervention/evaluation & $\begin{array}{l}\text { Grey Scale } \\
\text { level }\end{array}$ \\
\hline Increasing Insurance Coverage for Informal Sector Workers, Nicaragua & IIIA \\
\hline Mutual Health Organizations' Role in Increasing FP Knowledge and Use, Senegal & IIIB \\
\hline Improving Contraceptive Knowledge and Use Among Refugees, Pakistan & IIIB \\
\hline **Privatization in Reproductive Health Services, Pakistan & IV \\
\hline $\begin{array}{l}* \text { Subsidizing the Cost of FP/RH Services to Increase Use in Pakistan (see section on Social } \\
\text { Franchising) }\end{array}$ & IV \\
\hline $\begin{array}{l}\text { * Social Franchising and Vouchers to Increase IUD Use, Pakistan (see section on Social } \\
\text { Franchising) }\end{array}$ & IIIA \\
\hline $\begin{array}{l}\text { * Increasing use of FP/RH Services at the Facility and Community Level, Uganda (see } \\
\text { section on Facility-Based Service Delivery) }\end{array}$ & IIIB \\
\hline
\end{tabular}

*Indicates an intervention that is cross-referenced with another strategy. These interventions are described in the section on the primary strategy they apply, shown in parenthesis. 
Countries: This review identified seven financing-related interventions from four countries. Four of the seven interventions were in Pakistan, and there were also interventions in Nicaragua, Senegal and Uganda. Three of the interventions primarily employed other technical strategy strategies, so are discussed in those sections.

Supporting Evidence: The interventions identified were in the mid-range of strength of evidence, from two studies that are IIIA (evidence studies without randomization that include a control group), three studies that are IIIB (non-randomized studies without a control group), and two studies that are IV (non-experimental studies).

Interventions and Outcomes: There were a range of financing interventions identified in the review, including through insurance, health subsidies and privatization of health services through a national, not-for-profit NGO.

In Nicaragua, the Private Sector Partnerships-One project evaluated an intervention that worked to increase insurance coverage for informal sector workers (Hatt et al 2009). These informal sector workers were offered coverage, including FP/RH coverage, by the Nicaraguan Social Security Institute's health insurance program, delivered by microfinance institutions (MFI) that would market the insurance product, register users, and collect the premiums. Evaluation results showed that FP use among respondents increased from $64 \%$ at baseline to $66 \%$ at endline $(\mathrm{p}=0.03)$. There was no difference in FP use at endline between those with insurance and those without, nor was there significant difference in awareness of various FP methods. One indicator that did change was use of the three-month injectable, which was twice as likely to be used by those with insurance $(6 \%)$ as compared to those without insurance $(3 \%)(\mathrm{p}=0.018)$. Use of RH services (pap smears, mammograms, prostate exams, and HIV tests) increased from 39\% in 2007 to $42 \%$ in 2008 ( $\mathrm{p}=0.01$ ), though there was no significant difference by insurance status.

In Thiès, Senegal, an intervention was examined in which mutual health organizations' (MHO) increase FP knowledge and use for maternal health (Smith and Quijada 2006). The MHO was a community-based health insurance intervention that assisted low-income households to finance health care expenses, particularly in the rural or informal sectors. In the Thiès region of Senegal, less than one-third of MHOs covered FP services. Twenty-seven percent of women ages 15-49 in MHO member households were not MHO beneficiaries themselves. Knowledge and ever-use of FP was similar among MHO beneficiaries and non-beneficiaries, with $61 \%$ of beneficiaries and $55 \%$ of non-beneficiaries knowing of the pill and less than half familiar with other modern methods. The results of the intervention were modest, with MHO clients reporting higher monthly income, higher home ownership, and greater likelihood of having savings. There was no significant difference in awareness of FP methods by insurance status, and MHO client use of FP increased by two percentage points, from $64 \%$ at baseline to $66 \%$ at endline, and the likelihood of using an FP method did not differ by insurance status at endline.

In Pakistan, a health subsidy intervention was examined that worked to improve contraceptive knowledge and use among refugees from Afghanistan (Raheel et al. 2012). Upon arrival, Afghan refugees in Karachi were allocated to one of two national NGOs to help them meet their basic needs. One of the NGOs also provided their clients with $90 \%$ subsidies for medical care, while the other NGO encouraged their clients to use public and private (including NGO) health services for which they would pay out of pocket. This difference allowed researchers to examine whether offering a health subsidy improved contraceptive knowledge and uptake. The health subsidy had promising results, with $90 \%$ of those who received a subsidy reporting that they had heard of FP (compared to $45 \%$ in the non-subsidy group) and 54\% reporting that they used contraception (compared to $25 \%$ in the non-subsidy group). Also, $86 \%$ of women receiving a subsidy reported approving of FP (compared to $50 \%$ of those in the non-subsidy group) and $93 \%$ of those receiving the subsidy reported discussing the number of children they should have with their husband (compared to $49 \%$ in the non-subsidy group). 
A pilot intervention in Pakistan focused on privatization in reproductive health services (among other services), including family planning services, in Punjab province through contracting government service provision to a private, not-for-profit national NGO, the Punjab Rural Support Programme (PRSP) (Ravindran 2010). Through this initiative, PRSP had administrative and financial control over basic health units, and the money that had been previously allocated for government administration of these units was given to the NGO. Some innovations were introduced, including clustering 2-3 health units under one medical officer who lived close to their area of work and increasing medical officer salaries. PRSP also experimented with recruitment of female medical officers. Evaluations of the intervention found that there was a significant increase in basic health unit use after they began to open for regular hours and drugs were available. However, they were found to be providing only antenatal services and some delivery and post-partum care - pregnancy tests were available, but not contraceptive supplies or services. One issue identified was that national family planning programs were not integrated into the basic health care level. Family planning was a vertical program under the federal Ministry of Population Welfare and therefore PRSP did not have authority over staff of these programs.

The findings suggest that there is a modest evidence for CSO financing interventions, with mixed results. The most notable results were a modest increase in knowledge and awareness of contraception.

\section{Social Franchising}

"A social franchise is a network of private sector healthcare providers that are linked through agreements to provide socially beneficial health services under a common franchise brand" (Social Franchising for Health 2016). CSOs are often involved with social franchises, since franchisors are typically not-for-profit. Social franchises bring private sector services to clients at reduced prices and with standards and protocols that are instilled and monitored by the franchisor. However, many social franchises are still donor-dependent, even if just for free or subsidized commodities.

\section{TABLE 6}

Social Franchising

\begin{tabular}{|c|c|}
\hline Intervention/evaluation & $\begin{array}{l}\text { Grey Scale } \\
\text { level }\end{array}$ \\
\hline Increasing Access to FP in Poor Urban Areas, Pakistan & IIIA \\
\hline Social Franchising and Vouchers to Increase IUD Use, Pakistan & IIIA \\
\hline Improving Client Satisfaction, Nepal & IIIA \\
\hline Subsidizing the Cost of FP/RH Services to Increase Use, Pakistan & IV \\
\hline Social Franchising as a Public-Private Partnership Model, India & IV \\
\hline Increasing Uptake of LARCs Through Social Franchising, Tanzania & IV \\
\hline **Privatization in Reproductive Health Services, Pakistan & IV \\
\hline Social Franchising to Accelerate Access, Choice and Quality (Global) & IV \\
\hline $\begin{array}{l}\text { * Improving Quality Through Social Marketing, Pakistan (see section on Human Rights and } \\
\text { Quality of Care) }\end{array}$ & IV \\
\hline
\end{tabular}

*Indicates an intervention that is cross-referenced with another strategy. These interventions are described in the section on the primary strategy they apply, shown in parenthesis.

**This article is described in two sections because of description of separate interventions in one article 
Countries: Social franchising interventions were identified in four countries, plus one global review of research gaps. The country-specific interventions were largely located in Asia, with five interventions in Pakistan, one in Nepal, one in India and one identified in Tanzania.

Supporting Evidence: The interventions identified either fell into IIIA (three studies were non-randomized but had control groups) or IV (six interventions had evidence from non-experimental studies).

Interventions and Outcomes: The interventions identified in this review focus on issues around social franchising to reach the poor, increasing method-specific access, improving consumer satisfaction, and testing financing modalities to improve equity of services.

A study in Pakistan that looked at the impact of providing FP in poor urban areas through social franchise clinics led by an international NGO (name not specified) to increase access to FP in poor urban areas also found mixed results (Hennink and Clements 2005). Though knowledge of at least one modern method of contraception was already relatively high at $88 \%$, respondents in intervention sites had a statistically significant $5 \%$ increase in knowledge of modern methods of contraception compared to those in control sites at endline. Knowledge of the IUD and female sterilization saw the most increase, at $7 \%$ and $15 \%$ respectively, and the increase was statistically significant. The new clinics (the intervention sites) seemed to have an effect on the adoption of individual method types, though little overall impact on contraceptive prevalence. For example, ever and current use of condoms in study sites decreased slightly by two percentage points (while increasing in control sites by almost five percentage points) and female sterilization increased by 8 percentage points in the study sites, making it the second most common method, while it increased by only one percentage point in control sites. Users of the new clinics tended to be younger ( $<30$ years; $\mathrm{p}<0.05$ ), with a higher standard of living.

An intervention in Pakistan, implemented through the Marie Stopes Society "Suraj" social franchise, looked at social franchising and vouchers to increase access to IUD and whether these interventions make IUDs more affordable for low-income women (Azmat et al 2013b). Findings showed that CPR increased by 19.6\% (p-value $<0.001$ ) and modern method use increased by $22.7 \%$ (after adjusting by control site; $\mathrm{p}$-value $<0.001$ ). IUD use had the highest percentage change among all methods at $11.4 \%$ ( $\mathrm{p}$-value $<0.001$ ). The intervention sites also showed the greatest decrease in unmet need $(7.6 \%$; p-value $<0.001)$ and more than half of users were using a Suraj provider, including $76.4 \%$ of IUD users. Thirty-five percent of IUD users received their IUD for free through a voucher, and $41.7 \%$ paid out-of-pocket.

In Nepal, a pilot intervention was tested involving the creation of a fractional franchise network ("Sewa"), with the Nepal Fertility Care Center as franchiser, ${ }^{2}$ of nurses and paramedics to improve RH services (Agha et al 2007). The focus of the intervention evaluation document is on social franchising to improve client satisfaction and increase use of services. The Sewa franchise increased client satisfaction related to cleanliness (increasing statistically significantly from $37 \%$ to $65 \%$ ) while there was no significant change in control clinics. The same pattern was seen for satisfaction with availability of essential equipment (increased from $35 \%$ to $62 \%$ ), the range of services offered ( $40 \%$ to $71 \%$ ), privacy $(38 \%$ to $72 \%$ ), and quality of services (55\% to $77 \%$ ), with no significant increase in control sites for any of these indicators. However, client handling and service charges saw no change in satisfaction in either intervention or control sites. However, this does not seem to have translated into changes in current use of FP among married women ages 15-45 in either intervention or control areas.

2 In a fractional franchise, a specific package of services is added by a franchisor to a franchisee clinic, while the clinic also offers other services without the involvement of the franchisor (Thurston et al 2015). 
A case study on Greenstar Social Marketing's pay for performance (P4P) strategy in Pakistan, which was subsidzing the cost of FP/RH services to increase use, found that the scheme sold nearly $100 \%$ of the vouchers (which were intended for low-income pregnant women who had not previously delivered with a skilled health provider) (Bashir et al 2009). Vouchers covered facility-based delivery, four antenatal care (ANC) visits, one postnatal care visit, and one visit for FP services. Results found that there were high rates of facilitybased delivery and an estimated $20 \%$ increase in antenatal visits. Additionally, $79 \%$ of women returned after delivery for FP counseling and three-quarters of those women selected an FP method.

The Innovations in Family Planning Services project in India tested social franchising as a public-private partnership model that could help to increase access to and use of integrated FP/RH services in Uttar Pradesh (IFPS Technical Assistance Project 2012). The State Innovations in Family Planning Services Agency managed the network and the Hindustan Latex Family Planning Promotion Trust implemented it as the franchisor. A review documenting the development and implementation of the Merrygold Health Network found that the network had expanded and was operational in 36 districts in Uttar Pradesh, with 430 private service providers and nearly 10,000 community level workers. From October 2007 to February 2012, the network provided more than 756,000 ANC checkups, nearly 134,000 deliveries, more than 10,600 sterilizations, and more than 38,000 IUD insertions. There were also high reported levels of satisfaction with the services received.

The one article identified outside of Asia looked at the PSI/Tanzania Familia social franchise and its ability to increase uptake of long-acting reversible contraceptives through social franchising, as well as the operating challenges that the network faced (Population Services International 2012). The Familia network in Tanzania delivered more than 45,000 IUDs and more than 13,500 implants between March 2009 and the end of 2011. One of the main challenges was clinic staff: some staff left because of lack of time or interest, while some were terminated for performance reasons. The overall retention rate was $81 \%$, however, which exceeded the anticipated retention rate of of $75 \%$. An ongoing problem identified was that providers and facility owners don't always have motivation to offer more FP services, since FP services are often not as profitable as other services.

In Pakistan, the privatization of the health sector, including the privatization of reproductive health services, as part of the Structural Adjustment Programme was explored through case studies, including one on social franchising networks and how these initiatives contributed to equitable access to quality, comprehensive RH services (Ravindran 2010). The Pakistan social franchising interventions, Green Star Marketing Pakistan, a local non-profit NGO, and Key Social Marketing, funded through the Futures Group, showed mixed results: evaluations of the interventions showed that they increased access to contraceptive services, but found a mixed picture in relation to equity. A 2004 study found that the franchises became increasingly associated with a wealthier clientele, possibly because they were mainly located in urban areas. They were also found to offer mainly contraceptive services, not the wider range of RH services intended (by Green Star at least). A 2006 report also noted quality as a problem area.

Finally, a global review was identified that looked at MSI's country counterparts' social franchising interventions to accelerate access, choice and quality in 17 countries in Africa and Asia and analyzed progress against its four main output areas of access, efficiency, quality, and equity (Munroe et al 2015). The MSI global review found increases in service delivery statistics, from 25,335 clients receiving voluntary family planning services in 2008 to about 1,239,727 clients in 2014, with significant increases among all method types. MSI measured efficiency by CYPs generated each year by each franchise outlet. This has increased from 2008 (when the average was 178 CYPs per outlet) to 2014 (an average of 941 CYPs per outlet). Sixty-one percent of MSI's social franchise growth over this period was related to increases in efficiency, while the rest was 
due to increases in the number of franchisees. The mean quality score among audited franchisees increased significantly $(p<.002)$, from a mean score of 78.5 among 61 franchisees audited in 2011 to a mean score of 87.9 among 200 franchisees audited in 2014. This review also found that MSI's social franchising interventions helped reach new clients, with almost $41 \%$ of family planning clients stating that they had not been using a modern method in the three months prior to their visit and more than $46 \%$ of FP adopters stating that they had never previously used FP. More than $57 \%$ of clients lived on less than $\$ 2.50$ per day and $15 \%$ lived on less than $\$ 1.25$ per day in 2013, indicating that the interventions may have helped increase access for the poor.

The findings related to CSO social franchising are mixed, with general increases in awareness and knowledge of contraception, but inconsistent data on the impact on contraceptive uptake and use. There were also mixed findings on the effect of CSO social franchising on equitable access. Demand-side vouchers appeared to be affordable and acceptable for family planning users.

\section{mHealth}

CSOs have also been active in using mHealth (mobile health) to reach underserved populations. mHealth is an emerging field, classified as an "enhancement" intervention by the USAID High Impact Practices Initiative, that uses mobile and wireless technologies to strengthen other family planning interventions. The mHealth interventions found in the review focused on text message services to address queries about contraceptive methods.

\section{TABLE 7}

mHealth

\begin{tabular}{|c|c|}
\multicolumn{1}{c}{ Intervention/evaluation } & $\begin{array}{c}\text { Grey Scale } \\
\text { level }\end{array}$ \\
\hline Mobile Phones to Increase FP/RH Knowledge, Tanzania & IV \\
\hdashline Increasing FP Knowledge Through Texts, Philippines & \\
\hline
\end{tabular}

Countries: The review examined two interventions that used text message services to improve access to contraceptive information. These interventions were in the Philippines and Tanzania.

Supporting Evidence: The evidence is drawn from two relatively low strength but well-designed, nonexperimental studies (IV on the Grey Scale): a feasibility study in Tanzania and pre- and post-test study in the Philippines.

Interventions and Outcomes: A growing number of people have access to affordable mobile technologies and rapidly emerging communication networks. The two interventions found in the review were designed to provide health information and support directly to clients or to the general public through an automated SMS system (also known as text messaging) that provided information and addressed queries about family planning methods and clinic locations.

A pilot intervention in Tanzania, Mobile for Reproductive Health (m4RH), implemented by FHI 360 (an international NGO) in collaboration with local NGOs, used mobile phones to increase FP/RH knowledge (L'Engle et al 2013). M4RH is a free, opt-in automated family planning information platform via mobile phones, provided to the general public and promoted through FP clinics, fliers, and, later, through community health workers. M4RH was assessed for feasibility, reach and potential behavioral impact. During 
the 10-month pilot, m4RH received 4,813 questions about contraception by 2,870 different people. Each question was logged and followed to assess reach and possible impact. Among the $35 \%$ of unique users who reported their gender, $56 \%$ were female and $44 \%$ were male. Of the $32 \%$ of unique users who reported their age, approximately $60 \%$ were 29 years old or younger and $44 \%$ were between $20-29$ years old. Of the $29 \%$ who reported where they learned about $\mathrm{m} 4 \mathrm{RH}, 40 \%$ saw a poster, 19\% heard about it in a clinic, 18\% learned about it from a partner, relative, or friend, and $18 \%$ heard about it from a community health worker. About $25 \%$ of unique users requested information on natural family planning, followed by emergency contraception (21\%), implants (16\%), and condoms (16\%).

In the Philippines, lack of knowledge about methods, their use, mode of action, side effects and relative effectiveness was a barrier to contraceptive use by married women of reproductive age (Bautista, De Guzman, and Sescon 2006). The FamPlan Hotline was introduced by The Social Acceptance Project - Family Planning to increase FP knowledge and provide referrals (counseling was not offered through the hotline) via text, voice, or email, with the goal of increasing access to family planning nationwide. The hotline was implemented by a local NGO and between August 2004 and August 2006, 60,916 text messages and 4,131 phone calls were received, with most of the questions related to family planning (e.g. what is the safest method, how to detect one's fertile period, how to use the pill or injectable). Questions to the hotline increased significantly during media promotional activities.

The findings for CSO interventions that employed mHealth are drawn from operational research rather than rigorous evaluations. Nevertheless, findings suggest that mHealth services designed to respond to queries about contraceptive methods were popular and may have helped users find the best method for them.

\section{Human Rights and Quality of Care}

There is growing interest in implementing family planning using rights-based approaches, with guidance documents offered by the World Health Organization (WHO) $(2014 ; 2017)$ and others (Kumar and Hardee, 2017). Such programming focuses on ensuring that individuals and couples have the information and services they need to exercise their right to decide for themselves how many children to have and when, and to be treated equitably and without discrimination (Hardee et al., 2014). A cornerstone of rights-based family planning is the right to the highest attainable standard of sexual and reproductive health through programing that is accessible, available, affordable and high quality (OCHCR, 2016). There are 10 rights and empowerment principles (FP2020 2014; WHO 2014), with most programming to date focused on improving quality of care.

\section{TABLE 8}

Human Rights and Quality of Care

\begin{tabular}{|c|c|}
\hline Intervention/evaluation & $\begin{array}{c}\text { Grey Scale } \\
\text { level }\end{array}$ \\
\hline Human Rights as Part of RH Care, Nicaragua/EI Salvador & IIIA \\
\hline Quality FP and RTI Services for Urban Slum Populations, Bangladesh & IIIB \\
\hline $\begin{array}{l}\text { Strengthening Delivery of Quality RH Services to Women and Couples from Disadvantaged } \\
\text { Groups, Nepal }\end{array}$ & IIIB \\
\hline $\begin{array}{l}\text { Sustaining FP Practices Among Marginalized Groups, Nepal (see section on Human Rights } \\
\text { and Quality of Care strategy) }\end{array}$ & IIIB \\
\hline Improving Quality Through Social Marketing, Pakistan & IV \\
\hline
\end{tabular}


Countries: Five interventions were identified in five countries. Most were in Asia (namely Bangladesh, Nepal, and Pakistan), with one intervention identified in Nicaragua and El Salvador that focused on human rights.

Supporting Evidence: The evidence identified for this area is moderate, with most interventions rated IIIB (two interventions were non-randomized without control groups). There was one intervention rated higher (IIIA, non-randomized with a control group) and one lower (IV, a non-experimental study).

Interventions and Outcomes: In Nicaragua and El Salvador, the Human Rights in Reproductive Health Education initiative (established by the NGO Ipas Central America) worked with the University of El Salva $\neg$ dor and the National Autonomous University of Nicaragua in Managua to support the universities' efforts to incorporate human rights as part of $\mathbf{R H}$ care through their training interventions (Reyes et al. 2013). To pilot test and refine the educational materials, two pilot studies were conducted in Nicaragua, one with nursing students and one with medical school graduates. After a 5-day, 40-hour training, second year nursing students felt confident to act to change health services in the event they felt that human rights were being violated $(\mathrm{P}=0.04)$. However, there was no significant effect on their confidence to "make ethical decisions in difficult situations" or to "identify human rights violations in health services." New medical graduates received a three-day, 24-hour training course. Semi-structured interviews were used and results showed that participants identified several contextual factors that influenced their ability to protect and promote patients' rights. Factors included: "support from colleagues and supervisors, availability of material and human resources, and cultural issues related to gender inequality."

In Bangladesh, the Demand-based Reproductive Health Commodity Project used operations research to improve the quality of FP and RTI services for urban slum populations provided by NGO clinics in slum neighborhoods through capacity building (Talukder et al 2009). The intervention had positive results with an increase from $34 \%$ to $97 \%$ of clients who were asked by service providers about fears/ misconceptions about contraceptive methods and a 20 percentage point increase (from $9 \%$ to $29 \%$ ) in those that asked about previous symptoms, signs, and treatment suggestive of RTIs. The percent of clients given accurate information on the method they chose increased from $28 \%$ to $81 \%$ and the number told what to do if they experience side effects or other problems increased from $43 \%$ to $71 \%$. Client feelings changed as well, with improvements in clients' feelings about whether they were treated with dignity or respect, their comfort asking questions, and privacy and confidentiality. However, supplies still often fell short of demand, which remained a barrier to high quality.

A multi-component intervention in Nepal, the Valued Behavior for Healthy Families project, implemented by the Health Communication Partnership, including Johns Hopkins Bloomberg School of Public Health Center for Communication Programs and Save the Children/US and local NGO networks, aimed to strengthen the delivery of quality $\mathrm{RH}$ services to women and couples from disadvantaged groups (Health Communication Partnership Nepal 2006). One of the goals was to improve the quality of FP services delivered by providers in facilities and the community. The intervention used the Partnership Defined Quality (PDQ) approach, a rights based approach that aims to increase community ownership and involvement in the health facility to impact the quality and use of services. Using a PDQ process in 30 Village Development Committees in the project area, the intervention effectively changed community perceptions and helped to develop better understanding between health workers and the community. Community members also mobilized to address health facility quality problems with local resources, and demand that health facilities and outreach clinics provide regular and timely services. The project was later reviewed by the CORE Group to identify which project activities had been sustained after the end of the intervention (CORE Group 2009). The CORE Group found, through interviews and observation, that the Valued Behavior for Healthy Families' PDQ approach 
continued to be used by selected health facilities to improve the quality of health and FP services, two years after the end of the project.

A report on the Green Star social franchise in Pakistan, which worked to improve quality of FP services through social marketing, sought to assess the quality of service provision by using the Bruce-Jain framework (Gulzar et al 2008). The Green Star network's work to improve quality of care was positive overall, with observation of client-provider interactions showing that $83 \%$ of providers replying satisfactorily to client's questions, $73 \%$ providing visual privacy, and $62 \%$ providing auditory privacy; however, only $76 \%$ of clients reported that they felt the privacy was adequate. All clients felt that the provider was friendly and $97 \%$ thought the provider was easy to understand, but few $(10 \%)$ were asked if something was unclear. All clients were told about more than one method, $62 \%$ were informed about all four methods available at the clinic, and $86 \%$ received the method they chose.

The strength of evidence about CSOs implementing family planning using rights-based approaches is low, although with generally positive reporting from clients related to better treatment, greater confidence asking questions, and better counselling.

\section{Introducing and Scaling Up Fertility Awareness Methods}

Fertility awareness-based methods (FAM) of contraception are modern, effective, non-hormonal options for women who can't or choose not to use other methods. FAMs include the Standard Days Method (SDM), and Lactational Amenorrhea Method (LAM), and the TwoDay Method (not discussed in this section). SDM helps couples track the woman's menstrual cycle and avoid unprotected intercourse during her fertile period with a user-controlled aide such as Cycle Beads. It also can increase male engagement in FP/RH and couple communication, is low to no cost, and has failure rates (both correct use and typical use) that are similar to diaphragms and female and male condoms (Wright, Iqteit, and Hardee 2015). LAM is a short-term method for new mothers based on the natural effects of breastfeeding (particularly exclusive breastfeeding) on fertility. Breastfeeding suppresses the release of hormones necessary for ovulation and can protect a woman from pregnancy for up to six months after giving birth (Institute for Reproductive Health 2017).

Countries: Interventions were identified in four countries: India and three sub-Saharan African countries.

Supporting Evidence: The evidence supporting CSOs' involvement in introducing and scaling up SDM is moderate, ranging from two non-randomized studies with control groups (IIIA) and three non-randomized studies without control groups (IIIB).

\section{TABLE 9}

Introducing and Scaling Up Fertility Awareness Methods

\begin{tabular}{|c|c|}
\hline Intervention/evaluation & $\begin{array}{c}\text { Grey Scale } \\
\text { level }\end{array}$ \\
\hline Adding SDM to the Method Mix, Burkina Faso & IIIA \\
\hline Adding SDM to the Method Mix, India & IIIA \\
\hline Introducing the Standard Days Method, Ethiopia & IIIB \\
\hline Adding SDM to the Method Mix, Benin & IIIB \\
\hline Increasing use of LAM in India & IIIB \\
\hline
\end{tabular}


Interventions and Outcomes: The interventions all focused on introducing or increasing knowledge of SDM and LAM in the method mix. SDM was added to the method mix in Ethiopia, Burkina Faso, Benin, and India and LAM was introduced in India.

In Burkina Faso, Jhpiego and Institute for Reproductive Health (IRH), in collaboration with a local community mobilization NGO, implemented a pilot intervention in one NGO facility and two public facilities to explore the feasibility of adding SDM to the method mix (Bicaba et al 2005). Twenty-eight percent of providers reported some difficulty in providing the method, yet all providers felt SDM should be offered. Six months after enrollment in the study, $48 \%$ of clients reported that they were still using SDM, while $25 \%$ had discontinued use (24\% were lost to follow-up and 3\% were pregnant). There were proportionally more discontinuers at the rural, public facility (53\%), than at the urban NGO provider $(24 \%)$ or the urban public clinic $(11 \%)$.

Krishi Gram Vikas Kendra, supported by IRH, implemented an intervention to add SDM to the method mix in some of its project areas in Jharkhand, India (Institute for Reproductive Health 2008a). In the endline survey, more women in the two intervention blocks (Kanke and Ormanjhi) knew of SDM (27\% and 32\% respectively) compared to the control block (Burmu) (4\%). More women in Kanke (93\%) and Ormanjhi (96\%) knew where to obtain FP methods, compared to $80 \%$ of women in Burmu. However, only $18 \%$ of women in Ormanjhi and $9 \%$ of women in Kanke and Burmu knew sources for natural FP methods. Of the women in the study, 56\% were currently using any FP method, including 37\% using a permanent method, $11 \%$ using a spacing method, and 8\% using a traditional method (including 0.2\% using SDM in Burmu, 0.8\% using SDM in Kanke, and $1.8 \%$ using SDM in Ormanjhi). Of women who intended to use FP in the future, $1.8 \%$ in Kanke and $3.4 \%$ in Ormanjhi said they would use SDM (this was $0 \%$ in Burmu).

In Ethiopia, Pathfinder International Ethiopia worked with five local organizations to introduce the SDM into its community-based intervention (Bekele and Fantahun 2012). Health professionals and community-based reproductive health agents were trained on providing SDM and the community workers added CycleBeads to the basket of products they were already offering (including oral contraceptive pills and barrier methods), and incorporated it into educational and referral services. Results showed that, of those who adopted SDM, $80 \%$ had ever used any contraceptive method in the past, while $20 \%$ had no history of contraceptive use. Seventy percent of SDM users chose SDM because of its lack of side effects, $54 \%$ because of fear of side effects of other methods (particularly hormonal contraceptives), and 5\% because of ease of use. At the time of interview, $80 \%$ of clients were using SDM to avoid pregnancy and $20 \%$ had discontinued, for reasons including menstrual cycles falling outside of the 26-32-day range necessary for effective use, distrust of the method, and wanting to become pregnant.

Adding SDM to the method mix through a maternity hospital and NGO clinics was also looked at in Benin. Of the three clinics included in the study, the NGO Organization pour la Santé et Vie (Organization for Service and Life)/Jordan (OSV-Jordan) had the highest percentage of SDM users as a percentage of all methods provided (28.4\%), followed by the maternity hospital, HOMEL (3.6\%) and the NGO clinic Association Beninoise pour la Promotion de la Famille (Beninese association for the promotion of the family, or ABPF) (3\%). The study noted that the difference was likely attributable to OSV-Jordan's recruitment efforts, including organized community promotion activities, and to the speed and efficiency of not for profit sector decision-making, while the public clinic faced institutional changes and staffing turnover and the ABPF clinic also experienced staffing changes. Women largely reported receiving information on SDM through TV/ radio promotional activities at HOMEL (65.2\%) and OSV-Jordan (68.9\%), though at ABPF $66.7 \%$ of women reported community sensitization as their main source of information. Because SDM is a method for couples to use, the results were also collected for husbands/partners who largely reported that they received information 
from their female partner (68\%). Reasons for adopting SDM also varied by clinic. Husband opposition to other methods was cited by $50 \%$ of HOMEL clients who selected SDM, compared with only 5-6\% clients who selected SDM at the other clinics. The lack of health effects was cited by $37 \%$ of clients at the public clinic, $26 \%$ of clients at OSV-Jordan, and 15\% at ABPF.

To increase use of LAM in India, IRH collaborated with three NGOs (World Vision in Uttar Pradesh, URMUL Seemant in Rajasthan, and People's Rural Education Movement in Orissa) to offer LAM through their community level workers (Institute for Reproductive Health 2008b). In Uttar Pradesh, 15 master trainers and 47 community level workers were trained, and 742 women adopted LAM. Clients in the intervention communities reported being satisfied overall with the method. In Rajasthan, 23 master trainers and 269 community level workers were trained and 345 women adopted LAM. In Orissa, 32 master trainers and 497 community level workers were trained and 454 women adopted LAM. Respondents in all three project areas thought more SBCC was needed to support the introduction of LAM (though who the respondents were and what additions were needed varied among project areas). For example, in the Rajasthan area the client card (a card designed for the intervention to be handed out to clients during counseling with messages about LAM to take home with them) was not found to be useful, perhaps because of a high degree of illiteracy in the project area.

The strength of the findings about CSOs introducing or increasing access to fertility awareness contraceptive methods are moderate, but suggest these interventions increased knowledge about the methods, increased use of the methods, and increased acceptability among clinic-based and community-based providers.

\section{Social and Behavior Change}

Social and Behavior Change (SBC) interventions are designed to bring about behaviors that will improve individual and community health status and related long-term outcomes. They are common to most FP/RH interventions and use a range of communication channels aimed at individuals, sub-groups, or large regional or national populations to positively influence the demand for and use of family planning information and services. SBC approaches identified in this review included life skills and peer education; adult health education (group and one-on-one); school-based education; couple communication; community mobilization; working through gatekeepers; and mass media interventions targeted at a general public audience.

Countries: The 22 interventions identified were implemented in 20 countries: Asia (India, Bangladesh, Afghanistan, Nepal), Southeast Asia (Indonesia, Cambodia), Africa (Kenya, Uganda, Nigeria, Senegal, Zimbabwe, Zambia, Ethiopia, Mali, Madagascar, Botswana, Ghana), Eastern Europe and Central Asia (Georgia, Turkey) and Brazil. Eleven of these interventions were in India and 6 were in Bangladesh.

However, only eight of the interventions were primarily SBC interventions. Those are described here, while the others are described in the section on the strategy they primarily employed. Many of the interventions focused on adolescents (12), over half (15/22) were part of a larger multi-component intervention, and over half $(14 / 22)$ combined SBC with service delivery.

Supporting Evidence: The evidence found for these interventions drew from eight studies in the Grey IIIA category (non-randomized studies with control groups), seven studies that were Grey IIIB (non-randomized studies that had no control groups) and seven non-experimental studies (Grey IV).

Interventions and Outcomes: The review includes eight interventions with a primary focus on SBC. They include those that are designed and/or implemented by civil society organizations to change behaviors to improve sexual and reproductive health status. The interventions tended to report on two types of outcomes: increased contraceptive uptake and changes in contraceptive knowledge and attitudes. 
TABLE 10

Social and Behavior Change

\begin{tabular}{|c|c|}
\hline Intervention/evaluation & $\begin{array}{c}\text { Grey Scale } \\
\text { level }\end{array}$ \\
\hline \multicolumn{2}{|l|}{ Community } \\
\hline Increasing FP Use, Afghanistan & IIIB \\
\hline Effect of Self-help Groups on Maternal Health, India & IIIB \\
\hline Improving Urban Reproductive Health, India, Nigeria, Kenya and Senegal & IIIB \\
\hline Improving Community Involvement in $\mathrm{RCH}$, India & IV \\
\hline Communicating Women's Health Messages, Zimbabwe, Uganda, and Zambia & IV \\
\hline Increasing Acceptability of FP, Mali & IV \\
\hline $\begin{array}{l}\text { * Delivering FP-MCH Services to Poor and Underserved Communities in Bangladesh } \\
\text { (primarily in Facility-Based Service Delivery) }\end{array}$ & IIIA \\
\hline * Improving Urban SRH in Bangladesh (see section on Facility-Based Service Delivery) & IIIA \\
\hline * Improving Rural SRH in Bangladesh (see section on Facility-Based Service Delivery) & IIIA \\
\hline * Empowering Married Young Women, India (see section on Youth) & IIIA \\
\hline * Improving Adolescent RH, Botswana, Ghana, Tanzania, and Uganda (see section on Youth) & IIIB \\
\hline $\begin{array}{l}\text { * Influence of Community Engagement on Adolescent Reproductive Health, Republic of } \\
\text { Georgia (see section on Youth) }\end{array}$ & IIIB \\
\hline $\begin{array}{l}\text { * Mobilizing Faith-based Networks to Promote and Deliver FP Services, Ethiopia (see section } \\
\text { on Facility-Based Service Delivery) }\end{array}$ & IV \\
\hline $\begin{array}{l}\text { * Increasing Use of LAM in India (see section on Introducing and Scaling Up Fertility } \\
\text { Awareness Methods) }\end{array}$ & IV \\
\hline * Reproductive Health of Young Adults in India (see section on Youth) & IV \\
\hline \multicolumn{2}{|l|}{ Individual } \\
\hline Increasing Contraceptive Use Among Young Couples, India & IIIA \\
\hline Improving Maternal Health for Young Mothers, Kenya & IV \\
\hline $\begin{array}{l}\text { * Increasing Contraceptive Use Among Marginalized Urban Men, Bangladesh }(\text { see section } \\
\text { on Programming for Men) }\end{array}$ & IIIA \\
\hline $\begin{array}{l}\text { Building Life Skills to Improve Adolescent Girls' Reproductive and Sexual Health, Tigri and } \\
\text { Naglamachi, Delhi, India (see section on Youth) }\end{array}$ & IIIB \\
\hline * Improving Student Knowledge on SRH, India (see section on Youth) & IIIB \\
\hline * Improving FP/RH Services for Young Married Couples, Bangladesh (see section on Youth) & IIIA \\
\hline * Improving Youth SRH in India (see section on Youth) & IIIA \\
\hline
\end{tabular}

*Indicates an intervention that is cross-referenced with another strategy. These interventions are described in the section on the primary strategy they apply, shown in parenthesis. 


\section{Community}

In rural Afghanistan, the MSH intervention Rural Expansion of Afghanistan's Community-based Healthcare (REACH) implemented a smaller intervention called Accelerating Contraceptive Use with the goal of increasing FP use (Huber et al 2010). MSH worked with four local NGOs (Coordination of Humanitarian Assistance, Bakhtar Development Foundation, STEP Health and Development Organization, and the Agency for Assistance and Development of Afghanistan) to implement services. The NGOs worked with communities and local gatekeepers (e.g. community and religious leaders, community health workers, and so forth) to provide information about the safety and possible side effects of contraceptives, create a positive view of birth spacing, and develop culturally acceptable innovations. The REACH intervention saw increases in contraceptive use from 16\% to $26 \%$ over two years, and the Accelerating Contraceptive Use intervention increased contraceptive use by $24-27 \%$ over eight months. The largest method increase was in injectable contraceptives.

In India, the effect of self-help groups (SHG) on maternal health was examined using secondary analysis of national level data (Saha et al 2013). SHGs are the most prominent model for microfinance delivery in India. They are "promoted by the state governments, NGOs, a few regional rural banks, and specialized MFIs that use various models to make both group and individual loans (Saha et al 2013)." Results from the secondary analysis showed that almost 60\% of Indian villages have an SHG. Women in villages with an SHG had a 19\% higher likelihood of having an institutional delivery, and households in a village with a SHG had $48 \%$ higher odds of knowing at least one modern FP method and 19\% higher odds of having ever used FP.

The Urban RH Initiative, implemented by a consortium of local and international organizations, was designed to improve urban reproductive health in India, Nigeria, Kenya and Senegal through SBC activities, including demand creation activities (Speizer et al 2014). The types of media used and messaging and service delivery strategies differed for each country, based on baseline survey findings. The Urban Health Initiative in India focused on interpersonal communication activities, radio and television program messaging, and midmedia activities such as street plays and road shows. The Kenya Urban RH Initiative focused on changing social norms and barriers through community mobilization and mass media. In Senegal, l'Initiative Sénégalaise de Santé Urbaine focused on demand creation through community outreach workers, small group discussion, religious and community leader engagement, community theater and mass media. Finally, the Nigerian Urban RH Initiative focused on social mobilization through IPC, mass media, and branding of the program with a colorful logo and slogan. Midterm results showed that in India and Kenya, modern method use increased by just under one percentage point (from $36.7 \%$ to $37.6 \%$ in India and from $44.8 \%$ to $45.7 \%$ in Kenya). Larger increases were seen in Nigeria, where modern method use increased by 6 percentage points (from $23.3 \%$ to $29.8 \%$ ), and Senegal, where use increased by more than 5 percentage points (from $26 \%$ to $31.5 \%$ ). At the midterm in India, modern method use was significantly more likely $(\mathrm{p} \leq .05)$ if a woman recalled exposure to a CHW or to any UHI television program.

The Local Initiatives Program in India was managed by Management Sciences for Health (MSH), an international NGO, and three local NGOs (the Center for Research in Rural and Industrial Development, the Himalayan Institute Hospital Trust, and the Child in Need Institute), and worked to improve community involvement in reproductive and child health (Paxman et al 2005). Specifically, the intervention was designed to "stimulate community involvement in health care using local committees and health volunteers to create partnerships with other agencies (Paxman et al 2005)." All three local NGOs formed community partnerships to support the intervention, and more than 600 local RCH committees and 1,850 community health volunteers provided services to approximately 780,000 people. All three intervention areas had endline CPRs near or above $60 \%$, representing an average $78 \%$ increase in contraceptive use. Child immunization rates 
and antenatal care also increased, by $67 \%$ and $78 \%$ respectively. The intervention benefitted from the receipt of unexpected contributions, such as health personnel, clinic sites, and drug funds, from the government, NGOs and the community. These donations increased available services by an estimate of one-third.

The Women Connect! intervention was implemented by the Pacific Institute for Women's Health and the Annenberg Center for Communication at the University of Southern California with 29 NGOs in Zimbabwe, Zambia, and Uganda that wanted to learn to communicate women's health messages more effectively (Pillsbury and Mayer 2005). The intervention's goals included communications capacity building, information sharing, and helping women strengthen their organization's ability to achieve their objectives. The approach used information communication technology (ICT) and strategic use of media. Twelve of the 29 NGOs used traditional and mass media to carry out their activities, while the other 17 focused on ICT or ICT and traditional media., posters, flyers, and information sheets on specific women's health and empowerment themes.

Georgetown University's Institute for Reproductive Health's Fertility Awareness-Based Methods (FAM) intervention in Mali worked to increase the acceptability of FP and reduce unmet need by integrating SDM into FP services (Institute for Reproductive Health 2012). To do this, IRH partnered with a coalition of women's savings and loans associations called COFEMALI. The intervention used a social diffusion approach to train COFEMALI association leaders as peer educators and distributors of CycleBeads in their communities. Results included more than 2,000 home visits made in three months, 750 new SDM users who received CycleBeads from association leaders, and referrals of more than 3,440 women to the health facility for FP.

\section{Individual}

Pathfinder International's PRACHAR project in India worked to increase contraceptive use among young couples in three districts of Bihar through social norms change related to early childbearing (Daniel et al 2008). Nineteen local NGOs were involved with PRACHAR's implementation. Messages were shared with unmarried adolescents through a workshop and with newlywed couples through "infotainment parties." Group meetings and home counseling were also provided to young married women and men separately, and the intervention worked with community leaders, parents and in-laws. Results showed that contraceptive use in the intervention areas rose from $4 \%$ to $21 \%$, while in the comparison area it rose from $3 \%$ to $5 \%$. In the intervention areas, the belief that early childbearing is injurious to a mother's health rose from $17 \%$ to $74 \%$, versus $12 \%$ to $65 \%$ in the comparison areas. Women in the intervention areas increased their knowledge of fertile days from 18\% to 39\%, while in comparison areas the level of knowledge remained essentially unchanged at around $20 \%$.

Jhpiego, an international NGO, implemented an intervention in Kenya focused on improving maternal health for young mothers through young mothers' clubs (YMC) (Ndirangu et al 2015). For the YMCs, mothers gathered weekly to share challenges and experiences and to receive health education from health facility staff and community health workers. A study assessing whether the YMC intervention communicated safe motherhood and FP messages to young mothers found that knowledge of healthy child spacing (two years between delivery and next pregnancy) increased, from $84 \%$ at pre-test and $94 \%$ at post-test, but knowledge that a woman can start using FP immediately after delivery decreased, from 57\% to 46\%. Knowledge of the three elements necessary for LAM to be an effective method of FP increased significantly, from $18 \%$ at pre-test to $52 \%$ at post-test $(\mathrm{p}<0.001)$. Reporting of current use of FP also rose significantly, from $77 \%$ to $86 \%$ ( $p<0.001)$.

CSO-led SBC interventions included the creation of local committees and self-help groups and work with local gatekeepers. The evidence for the SBC interventions was fairly strong, with reported changes in knowledge, attitudes and awareness about birth spacing and family planning, and changes in behavior resulting in increased 
uptake of contraception, and/or changes in sexual behavior or contraceptive behavior. There were also outcomes related to increased capacity of service providers and of CSOs to undertake or support social and behavior change communication.

\section{Youth}

According to the FP High Impact Practices enhancement brief on adolescent-friendly contraceptive services, most women begin sexual relationships between the ages of 15 and 19 (High-Impact Practices in Family Planning 2015). This puts them at great risk of unwanted pregnancy or sexually transmitted infections. There is currently a global emphasis on engaging and empowering youth to start using modern contraception and to increase their access to SRH information and services, helping them to delay pregnancies and plan their lives as they see best for themselves. Adolescent-friendly contraceptive services are also noted as a program enhancement that can intensify the impact of FP High Impact Practices (High-Impact Practices in Family Planning, 2015).

Countries: Twelve interventions with a focus on youth were identified globally, with a large number in Asia, particularly India. Interventions were also identified in Bangladesh, Botswana, Ghana, Tanzania, Uganda, and the Republic of Georgia.

Supporting Evidence: All the interventions except for one had moderate evidence on the Grey scale, in the IIIA and IIIB categories. The exception was rated lower, in the IV category.

Interventions and Outcomes: The youth-focused interventions fell into four areas: community-based, schoolbased, facility-based, or multi-location interventions. The largest grouping was community interventions, all of which were all located in India. These interventions were diverse, working with both married and unmarried youth on issues ranging from community influence on support and skill building, to decision-making, approaches to reach married youth, and reducing RTIs. The school-based intervention looked at building student knowledge on reproductive health matters. The facility-based interventions looked at improving knowledge among youth and building provider capacity to work with youth in India and reaching young married couples in Bangladesh.

The multi-location interventions were much more diverse in setting and topic. They included two interventions focused on African Youth Alliance interventions, the First-time Parents Project in India focused on reaching young married women, and community engagement strategies in the Republic of Georgia.

\section{Community Level}

Four community level interventions were implemented in India by local CSOs in collaboration with the International Center for Research on Women's Improving the Reproductive Health of Married and Unmarried Youth in India intervention. An intervention by the Foundation for Research in Health Systems in India focused on married adolescents, with both supply and demand components, looking at whether social moblization or government services influence adolescents' $\mathbf{R H}$ in rural Maharashtra, India (Pande et al 2006). They found that in sites that addressed demand issues through social mobilization, RH outcomes generally improved more. Improvements included support of mothers-in-law and awareness of husbands about basic maternal care issues such as the importance of antenatal care and treatment seeking for problems during pregnancy and childbirth. However, similar increases in awareness of FP methods were seen in all intervention sites, regardless of whether they used social mobilization.

The Christian Medical College in India looked at reducing reproductive tract infections among married youth in rural Tamil Nadu. The two avenues that were examined included diagnosis and home treatment by 


\section{TABLE 11}

Youth

Intervention/evaluation

Grey Scale

level

Community

\begin{tabular}{|c|c|}
\hline $\begin{array}{l}\text { Social Moblization or Government Services: What Influences Adolescents' RH in Rural } \\
\text { Maharashtra, India? }\end{array}$ & IIIA \\
\hline Reducing Reproductive Tract Infections among Married Youth in Rural Tamil Nadu, India & IIIA \\
\hline $\begin{array}{l}\text { Building Life Skills to Improve Adolescent Girls' Reproductive and Sexual Health, Tigri and } \\
\text { Naglamachi, Delhi, India }\end{array}$ & IIIB \\
\hline $\begin{array}{l}\text { Reproductive and Sexual Health Education, Care and Counseling for Married Adolescents in } \\
\text { Rural Maharashra, India }\end{array}$ & IIIB \\
\hline \multicolumn{2}{|l|}{ School-based } \\
\hline Improving Student Knowledge on SRH, India & IIIB \\
\hline \multicolumn{2}{|l|}{ 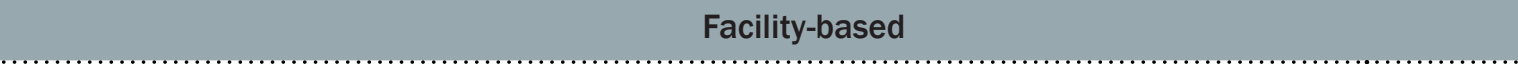 } \\
\hline Improving FP/RH Services for Young Married Couples, Bangladesh & IIIA \\
\hline Improving Youth SRH in India & IIIA \\
\hline \multicolumn{2}{|l|}{ Combination of Facility/School/Community } \\
\hline Empowering Married Young Women, India & IIIA \\
\hline Improving Adolescent $\mathrm{RH}$, Botswana, Ghana, Tanzania, and Uganda & IIIB \\
\hline Africa Youth Alliance Impact on Youth SRH Behavior, Uganda & IIIB \\
\hline $\begin{array}{l}\text { Influence of Community Engagement on Adolescent Reproductive Health, Republic of } \\
\text { Georgia }\end{array}$ & IIIB \\
\hline Reproductive Health of Young Adults in India & IV \\
\hline
\end{tabular}

community health aids trained by senior gynecologists versus referral to female doctors who would periodically provide treatment at a subcenter clinic (Pande et al 2006). Health aids alone treated about 53\% of symptomatic women, with $35 \%$ cured of symptoms, compared to about $28 \%$ treated and $20 \%$ cured of symptoms in the referral arm. However, follow-up was weaker in the health aid arm. Both groups performed similarly on changes in RH knowledge and in RTI prevalence, but health aides were more accessible and reached more women than doctors.

Results from a comprehensive community-based intervention to build life skills to improve adolescent girls' reproductive and sexual health, implemented by the NGO Swaasthya in Delhi, India showed that most of the intervention components - particularly related to social support groups, skills-building, and oneon-one communication with field workers - were associated with improved outcomes for girls (Pande et al 2006). Results, however, were weaker when tested for replicability in another location. Sustainability was also tested in the pilot location: outcomes and processes were largely sustained, but the intervention itself was not, as the field workers left and several of the intervention components ended. 
Finally, the KEM Hospital Research Centre implemented an intervention related to the reproductive and sexual health education, care and counseling for married adolescents in rural Maharashra, India (Pande et al 2006). Under this intervention, more than 90\% of eligible couples attended at least one session on reproductive health education and about 75\% attended four of the seven sessions. However, less than $50 \%$ attended the full series of seven sessions because of issues such as child care, lack of permission from family elders, and seasonal migration. Those who completed four sessions and those who completed the full series had similar increases in RH awareness, however. There was also an observed increase in the use of clinics services, with $70 \%$ of referrals coming from the health education sessions.

\section{School-based}

An assessment of the Adolescent Reproductive Sexual Health Education Package intervention to improve student knowledge on SRH, originally developed at the Child Development Centre in Kerala, India, found that there was a statistically significant increase in the SRH-related knowledge of both boys and girls (Nair et al 2011). Additionally, there was a decrease in poor knowledge among both girls $(64.1 \%$ to $8.3 \%)$ and boys $(37.7 \%$ to $3.5 \%)$.

\section{Facility-based}

In Bangladesh, an intervention implemented by EngenderHealth in collaboration with the government and NGO service delivery systems aimed to reduce social and cultural barriers to independent decisionmaking and improve FP/RH services for young married couples by integrating their gatekeepers into the intervention (Khatun et al 2011-2012). Overall findings were mixed, but an increase was observed in the number of contraceptives received from NGOs in intervention sites compared with the control area. CPR also increased 3\% from baseline in the intervention area. There was a slight decrease in ANC knowledge between baseline and endline, but awareness of HIV/AIDS increased by $8 \%$ and knowledge of condom use increased. However, $30 \%$ of women in the intervention area still didn't know how to avoid HIV/AIDS at the end of the intervention.

The DISHA intervention in India, implemented by ICRW and six local NGO partners, worked to improve youth SRH services and access, improve youth skills and capacity through peer education, improve the enabling environment through community support, and build the capacity of the partner NGOs (Kanesathasan et al 2008). By endline, $63 \%$ of females and $72 \%$ of males knew the legal age of marriage for girls in India - a 30\% increase for both groups. In Bihar, more than half of all female youth initially disapproved of contraceptive use in marriage, but this dropped to $12 \%$ at endline. Youth exposed to DISHA were also more likely than nonexposed youth to know how to access contraceptives (15\% more likely for condoms and 17\% more likely for contraceptive pills) and to think that young married couples should have access to contraceptives (5\% more likely). Depth of exposure to the intervention also made a difference - for example, females with individualized program exposure were almost four times more likely than those with generalized program exposure to believe the ideal age of marriage is 18 years or older (adjusted odds ratio of 5.89 and 1.53 respectively, $\mathrm{p}<.05$ ).

\section{Combined Interventions}

The combined interventions were broader in geographic scope, including programs in India, Botswana, Ghana, Tanzania, Uganda and the Republic of Georgia.

In India, the First-time Parents Project, implemented by the Population Council in partnership with the Child in Need Institute, the Deepak Charitable Trust, and the International Institute for Population Sciences, tested an integrated package of health and social interventions to empower married young women 
by improving the SRH knowledge and practices of young, newly married women, first-time pregnant women, and first-time mothers in two rural settings (Diamond Harbour Block in the state of West Bengal and Vadodara Block in the state of Gujarat) (Santhya et al 2008). The intervention primarily included providing information to married young women through home visits, counseling sessions in clinic settings, young women's discussion groups, and community activities including health fairs. Husbands also received information through home visits by male outreach workers and discussion groups. Gender attitudes were improved at endline across all groups, but to varying degrees. In Diamond Harbor, there was a $42 \%$ increase among those who were exposed to the intervention who thought that wife beating was not justifiable, compared to a $38 \%$ increase in the experimental non-intervention group and a 35\% increase in the control group. In Diamond Harbor, there was a similar increase across all groups in the likelihood of using contraceptives to delay a first pregnancy. In Vadadora, the intervention group was slightly more likely to use contraceptives to delay a first pregnancy at endline than at baseline, while the other groups were less likely to use contraceptives to delay a first pregnancy at endline than baseline.

The African Youth Alliance had interventions in Botswana, Ghana, Tanzania, and Uganda focused on the broad themes of policy and advocacy, SBC, youth friendly services, institutional capacity building, and integration of services into livelihoods in order to improve adolescent RH (Daniels 2007). The results from a multicountry evaluation found that there were significant, positive effects, particularly among females, on condom use at first sex, always use of condoms with current partner, and modern contraceptive use at first and last sex.

An evaluation in Uganda looked at the African Youth Alliance's impact on youth SRH behavior and found that girls exposed to AYA were 13 percentage points more likely to report using a condom the last time they had sex, and 10 percentage points more likely to report that they consistently use condoms with their current partner (Karim 2009). AYA-exposed females were also significantly more likely at endline to have used a condom at last sex, compared to baseline (27\% to $54 \%$ ). Although the likelihood of using a condom at last sex also increased for men (by 12 percentage points), overall AYA had a significant impact on females but not on males.

In the Republic of Georgia, CARE International, in collaboration with two local NGOs, implemented the Guria Adolescent Health Project, an intervention focused on the influence of community engagement on adolescent reproductive health and social norms (Tavadze et al 2008). Intervention strategies included promoting community support for adolescent reproductive health, building health provider capacity to meet the needs of adolescents, and using theatre to promote community dialogue about social norms. The intervention saw an increase from $43 \%$ to $93 \%$ in awareness that unwanted pregnancies are preventable. Adolescents reported that they had more accurate contraceptive information and knew more methods of contraception than before the intervention. Adolescents also reported that service quality had improved at facilities, and doctors and nurses felt more confident and open to treating adolescents after receiving capacity building training on FP counseling and youth friendly services. Both adults and adolescents reported improvements in how they communicate about contraceptives.

The Reproductive Health of Young Adults in India Project, implemented by Pathfinder International in partnership with four local NGOs brought training and knowledge to almost 22,000 adolescents and informed 3,571 young couples how to delay their first pregnancy and space subsequent births (Wilder et al 2006). It also reached more than 2,800 parents and other influential adults and 23,000 other individuals through outreach activities such as community street plays, workshops, and so forth. The model was later replicated by the PRACHAR project, which reached more than 90,000 adolescents and young adults. Reported intentions to delay first pregnancy after marriage increased from 55\% to $85 \%$ among girls who participated in the program and $57 \%$ to $73 \%$ among boys. There were also large increases in positive opinions about using contraception. 
Overall, there were a wide range of adolescent-friendly contraceptive programs provided at the community, school, and facility levels, and as part of larger interventions. There were mixed results for the activities at the community level, and better results were seen for interventions that focused on reaching individuals. Overall, the combined interventions reported stronger results than the others on improved contraceptive knowledge, awareness and use.

\section{Programming for Men}

It is important for men to be involved in $\mathrm{FP} / \mathrm{RH}$ interventions when possible so that they also have access to FP/RH information and services. The interventions tailored for men identified in this review were peerdelivered educational interventions to increase contraceptive uptake. In these interventions, the focus was on addressing barriers around acceptability by working through peers and community educators, and on increasing accessibility by providing services that are convenient for the workplace.

\section{TABLE 12}

Programming for Men

Intervention/evaluation

Increasing Male Knowledge of FP, Malawi

Increasing Contraceptive Use Among Marginalized Urban Men, Bangladesh
Grey Scale level

IIIA

IIIA

Countries: The review includes two interventions that focus specifically on targeting men to change their attitudes and use of contraception in Malawi and Bangladesh.

Supporting Evidence: The evidence supporting these two interventions comes from project-specific, quasiexperimental studies with control groups (Grey IIIA).

Interventions and Outcomes: In Malawi, the Male Motivator Project, implemented by Save the Children, worked to increase male knowledge of FP, particularly among the husbands of women who were often excluded from other interventions (Shattuck et al 2011). The empirically validated information-motivationbehavioral skills model was used. Before the intervention, none of the men were using contraception with their wife. Post-intervention, $78 \%$ of men in the intervention arm were using family planning methods, compared to $59 \%$ in the comparison arm. Of those using contraception in the intervention arm, 56\% used condoms, $41 \%$ used injectables, and 14\% used birth control pills.

In Bangladesh, the FRONTIERS Project and the NGO Service Delivery Program conducted an intervention to increase contraceptive use among marginalized urban men, particularly among rickshaw drivers, through an educational campaign (Bhuiya et al 2007). Experiment group I received an educational campaign from community educators and improved access to condoms; experiment group II received the educational campaign only; and a control group received no intervention. The intervention achieved significant changes in attitudes and behavior in the intervention sites. Seventy-eight percent of those in experiment group I agreed at baseline that delaying a first pregnancy was a good thing, compared to $92 \%$ at endline $(\mathrm{p}<0.001)$, with an increase in experiment group II from $70 \%$ to $88 \%$ ( $p<0.001)$. Also, use of contraceptive methods increased significantly, particularly for condom use. In experiment group I, use of any method increased from $68 \%$ to $81 \%(\mathrm{p}<0.001)$ and use of condoms increased from $5 \%$ to $19 \%(\mathrm{p}<0.001)$. Use of no method also decreased significantly in this group, from $32 \%$ to $20 \%$ ( $p<0.001$ ). There were small increases in use of any method in experiment group II and in the control group as well, but they were not significant. 
Overall, CSO interventions related to increased male involvement in $\mathrm{FP} / \mathrm{RH}$ programs were focused on increasing men's sense of responsibility for and access to contraception, and promoted positive changes in men's attitudes and support for family planning.

\section{Advocacy/Accountability}

Advocacy is defined as a set of actions undertaken by a group of committed individuals or organizations to introduce, change, or obtain support for specific policies, programs, legislation, issues, or causes. Accountability refers to the formal and informal procedures, norms and structures in a political system that require those in power to explain their decisions and ensure remedy for any failures to discharge their duties. Advocacy and accountability interventions are critical to create an enabling environment to effectively support the delivery of high quality FP/RH programs and services.

The review found two types of advocacy and accountability interventions: (1) capacity building to engage in policy and planning processes; and (2) CSO led assessment (community scorecards) and monitoring.

\section{TABLE 13}

Accountability/Empowerment

\begin{tabular}{|c|c|}
\hline Intervention/evaluation & $\begin{array}{c}\text { Grey Scale } \\
\text { level }\end{array}$ \\
\hline \multicolumn{2}{|l|}{ Capacity Building } \\
\hline Increasing NGO Capacity in SRH, Nigeria & IIIB \\
\hline \multicolumn{2}{|c|}{ CSO-led Assessment and Monitoring } \\
\hline Improving Provider Accountability, Uganda & IIIA \\
\hline Supporting Civil Society to Improve SRH Services, Tanzania & IIIB \\
\hline Community Monitoring, Pakistan & IIIB \\
\hline Improving Health Services Through Community Score Cards, India & IV \\
\hline
\end{tabular}

Countries: The review includes five interventions on CSO and NGO advocacy and accountability. These interventions were implemented in India, Pakistan, Uganda, Tanzania, and Nigeria.

Supporting Evidence: The evidence supporting these interventions generally comes from project-specific studies focused on process outcomes such as capacity built or service or budget level changes achieved. The five interventions identified in this review included one non-randomized study with a control group (Grey IIIA), three non-randomized studies without a control group, and one non-experimental study. Across all interventions, the link to changes in contraceptive use was indirect and the causal pathway was not articulated.

Interventions and Outcomes: The interventions identified in this strategy include training and capacity building of advocates and community members to understand political processes, and activities to increase community-led issue identification, collaborative problem-solving and more targeted advocacy actions.

Capacity Building

In Nigeria, an intervention to increase NGO capacity in SRH advocacy and policy was conducted by the national NGO the Association for Reproductive and Family Health, with 12 NGOs in three states 
(Momoh et al 2015). After the intervention, 93\% of those trained reported conducting post-training advocacy activities, including sensitization of health workers (62\%), stakeholder advocacy (38\%), advocacy to the State Ministry of Women Affairs (17\%), among others. Sixty-three percent of trained staff reported that they experienced challenges in the advocacy process including financial constraints (89\%) and time constraints (11\%). The three most utilized advocacy methods were phone calls $(28 \%)$, face to face meetings (26\%) and networking with other organizations for stronger impact (17\%).

\section{CSO-Led Assessment and Monitoring}

In Uganda, an intervention was conducted by local NGOs to examine the effectiveness of community-based monitoring to improve provider accountability (Bjorkman and Svensson 2009). The NGOs facilitated village and staff meetings within 50 communities that looked at the status of health service delivery and developed a plan to identify and address problems. This was meant to begin a process of community-based monitoring that the communities would then be responsible for sustaining. After a year, there was a $20 \%$ increase in use of general outpatient services at treatment facilities and absenteeism at treatment facilities decreased by 13 percentage points. The number of patients seeking antenatal care increased by $19 \%$, as did the number seeking family planning $(22 \%)$. There was also evidence of more engagement in treatment communities and more extensive monitoring of the health unit.

In Tanzania, Pathfinder International worked with Sikika, a local CSO, to implement an intervention supporting civil society to improve SRH services through use of a Citizen Report Card (CRC) to inform the design of advocacy plans (Pathfinder International 2013). The results of the CRC showed that of the 12\% of respondents who had not visited local public health facilities for FP services within the previous six months, $47 \%$ cited unfriendly services and $13 \%$ cited frequent lack of services as reasons. Of the small percentage (5\%) surveyed who responded that they did not receive the FP method they were seeking, 64\% said stock-outs were the main reason and 15\% reported lack of a skilled provider. Twenty-nine percent paid a user fee, which is contrary to the Tanzanian policy guaranteeing free FP services in the public health sector.

In Pakistan, the Health and Nutrition Development Society, a not-for-profit, conducted a community monitoring intervention within their existing reproductive health projects to examine how community monitoring works in an NGO and how communities respond to a community monitoring mechanism (Baloch and Ali 2015). Results from participant interviews showed that NGOs shared project goals with participants $(87 \%)$, that participants knew about project indicators $(76 \%)$, roles and responsibilities were clearly distributed $(76 \%)$, and that participants knew that community monitoring systems existed and were part of NGO projects (95\%). Additionally, 54\% of respondents reported that health facilities were visited weekly by Community Monitoring Committee members and that the CMC also met with staff on a regular basis (65\%), recorded client concerns (78\%), gave direction to staff when needed (48\%), and made joint plans with the NGO (87\%).

In India, the Center for Good Governance, Hyderabad, and the Andhra Pradesh Rural Poverty Reduction Project implemented a pilot intervention to improve health services through community score card use to assess the performance of primary health centers (Misra et al 2007). The intervention findings indicated systemic and support-level weaknesses in health care delivery, including low scores for staff behavior and working style, hours of operation and availability of doctors and staff (including both presence of staff as well as the suitability of the official hours compared to community needs), poor accountability, and weak responsiveness. Community members also reported that medicine prescribed by doctors was not distributed at the primary health center and that there was poor transparency of the medicines available. It was also found that community members had low awareness of their service entitlements, standards, or other government schemes. 
Most of these interventions were focused on building the capacity of CSOs and facilitating interventions related to community engagement and participation. The evidence to support these types of interventions was generally weaker and tended to focus on process outcomes such as capacity building and positive statements made in favor of family planning. 


\section{Summary of Key Outcomes from CSO Engagement in FP/RH Programming}

This review identified a wide range of interventions undertaken by CSOs to strengthen family planning programs. The interventions were mainly related to service delivery, financing, social franchising, mHealth, human rights and quality of care, introducing and increasing access to fertility awareness methods, social and behavior change, youth, programming for men, and accountability/empowerment. Given the range of interventions and the varied ways they were assessed; the strength of evidence was wide-ranging.

Most examples of CSOs strengthening family planning services were found under three types of interventions: service delivery, youth, and social and behavior change. The most common type of intervention was service delivery (including facility-based, community-based and mobile outreach), with 13 examples identified. The second most common type of CSO intervention was related to adolescent programming, including community-, school- and facility-based interventions and combinations of the three, with 13 examples identified. The third most common type of $\mathrm{CSO}$ intervention for FP/RH programming related to social and behavior change, with eight examples identified.

The evidence was strongest for interventions related to building the capacity of CSOs and NGOs to expand the provision of family planning services, with strong increases seen in $\mathrm{mCPR}$ in both rural and urban settings. CSO-led social and behavior change interventions also reported changes in knowledge, attitudes and awareness about birth spacing and family planning, and behavior changes including increased uptake of contraception and other changes in sexual behavior or contraceptive behavior. The combined interventions for adolescent-friendly contraceptive programs reported stronger results on contraceptive knowledge and awareness and improved contraceptive use than the single-strategy interventions. Many of the successful programs were embedded within larger programs that involved a range of interventions and stakeholders (including international CSOs and government). This suggests that CSOs play an important role in expanding the provision of family planning services and social and behavior change interventions.

The strength of evidence for other interventions was modest and tended to report on increased knowledge about family planning, increased client satisfaction and acceptability, and increased acceptability of contraception by providers, as well as process outcomes such as increased capacity of CSOs. Many of the examples included were pilot projects or operational research on innovative ways of working (e.g. mHealth, vouchers, mobile outreach, and SDM) that have potential for scale up. This suggests that CSOs play an important role in piloting new approaches and programming for FP/RH, and offer insight into implementation and effectiveness for scale up.

Civil society plays a diverse role in the provision of family planning programs, with interventions that promote both supply and demand, as well promoting enabling environments in communities and the health service and policy worlds. This diversity of roles places CSOs between the health system and the communities they serve, where they can expand service provision and link the community to the health system. CSOs are accountable to the state as a functioning part of health care delivery, but also to the communities they represent and serve.

Underlying this unique position is the assumption that civil society is able to work independently, without impairment. Supporting a strong and free civil society is essential to enabling them to play their dual function. 


\section{Evidence Gaps in CSO Programming for $\mathrm{FP} / \mathrm{RH}$}

This review identified several knowledge gaps in the literature that point to the need for improved documentation and research. Many CSO activities and interventions are not documented or assessed, or are not publicly available, and therefore could not be included. This is particularly the case for interventions not directly related to service delivery or health systems strengthening, such as accountability and empowerment. The high-grade evidence that was found tended to be derived from larger programs as part of a project evaluation or ongoing, wider institutional program monitoring. There are several examples of pilots and operational research that look at the implementation of an activity and that focus on feasibility and acceptability but give little attention to effectiveness and impact. 


\section{Conclusion}

The results from this literature review indicate that CSOs have a unique role to play in family planning programs, and have great potential to help test innovations and aid in scale-up of proven programs. CSO interventions related to service delivery, youth programming, and social and behavior change show significant contributions to improved access to family planning programs and increased knowledge and awareness, contraceptive use, and client satisfaction. Moreover, the interventions captured in this review also show the role CSOs play in testing new ways of programming to advance the provision of full, free, and informed contraceptive choice. However, many of the interventions that included a strong contribution from civil society were multi-stakeholder initiatives with limited description of the specific inputs of each stakeholder, making it challenging to determine the exact role and contribution of individual stakeholders, including civil society. 


\section{References}

Agha, Sohail, Ali Mehryar Karim, Asma Balal, Steve Sosler. The impact of a reproductive health franchise on client satisfaction in rural Nepal. Health Policy and Planning 2007; 22:320-328

Alam et al. Impact of dropout of female volunteer community health workers: An exploration in Dhaka urban slums. BMC Health Services Research 2012 12:260.

Azmat, Syed Khurram (a), Waqas Hameed, Ghulam Mustafa, Wajahat Hussain, Aftab Ahmed, Mohsina Bilgrami. IUD discontinuation rates, switching behavior, and user satisfaction: findings from a retrospective analysis of a mobile outreach service program in Pakistan. International Journal of Women's Health 2013:5 19-27.

Azmat, Syed Khurram (b), Tasneem Shaikh B, Hameed W, Mustafa G, Hussain W, et al. (2013) Impact of Social Franchising on Contraceptive Use When Complemented by Vouchers: A Quasi-Experimental Study in Rural Pakistan. PLoS ONE 8(9): e74260. doi:10.1371/journal.pone.0074260.

Gul Muhammad Baloch and Mumtaz Ali. Community Monitoring in Reproductive Health Projects: Case Study of a Health Sector NGO in Pakistan. VFAST Transactions on Education and Social Sciences Volume 7, Number 1, pp.05-12, May-June,2015.

Bashir, Hamid, Sarfaraz Kazmi, Rena Eichler, Alix Beith, Ellie Brown. September 2009. Pay for Performance: Improving Maternal Health Services in Pakistan. Bethesda, Maryland: Health Systems 20/20 project, Abt Associates Inc.

Bautista, Felix S., Eleanora M. De Guzman, Jose Narciso Melchor C. Sescon. 2006. The FamPlan Hotline: Making Family Planning Information Just a Text Away to Filipinos Nationwide. The Social Acceptance Project - Family Planning (Academy for Educational Development).

Bekele, Biruhtesfa and Mesganaw Fantahun. The Standard Days Method®: an addition to the arsenal of family planning method choice in Ethiopia. J Fam Plann Reprod Health Care 2012;38:157-166. doi:10.1136/jfprhc-2011-100116

Bhuiya, Ismat, Mizanur Rahman, Ubaidur Rob, M E Khan, Zahiduzzaman. Increasing Dual Protection among Rickshaw Pullers in Bangladesh. 2007. Population Council.

Bicaba, Abel, Barbara Rawlins, Rebecca Dineen, and Boubacar Ouedraogo. The acceptability and feasibility of introducing the Standard Days Method (SDM) of family planning in reproductive health clinics in Burkina Faso, West Africa. Jhpiego. July 2005.

Bjorkman, Martina and Jakob Svensson. Power to the People: Evidence From a Randomized Field Experiment on Community-Based Monitoring in Uganda. The Quarterly Journal of Economics, May 2009.

CORE Group, March 2009. Creating Healthy Families in Nepal: Sustaining Family Planning Practices Among Marginalized Groups.

Dalious, Mike and Ramakrishnan Ganesan. 2015. Expanding Family Planning Options in India: Lessons from the Dimpa Program. Bethesda, MD: Strengthening Health Outcomes through the Private Sector Project, Abt Associates.

Daniel, Elkan E., Rekha Masilamani and Mizanur Rahman. The Effect of Community-Based Reproductive Health Communication Interventions on Contraceptive Use Among Young Married Couples in Bihar, India. International Family Planning Perspectives,2008,34(4):189-197

Daniels, Ugochi. Improving Health, Improving Lives: Impact of the African Youth Alliance and New Opportunities for Programmes. African Journal of Reproductive Health Vol. 11 No.3 December, 2007. 
Duvall S, Thurston S, Weinberger M, Nuccio O, Fuchs-Montgomery N. Scaling up delivery of contraceptive implants in sub- Saharan Africa: operational experiences of Marie Stopes International. Glob Health Sci Pract. 2014;2(1):7292. http://dx.doi.org/10.9745/GHSP-D-13-00116

Eva, Gillian and Thoai D. Ngo. MSI Mobile Outreach Services: Retrospective evaluations from Ethiopia, Myanmar, Pakistan, Sierra Leone and Viet Nam. London: Marie Stopes International, 2010.

Evidence to Action (E2A). Program Brief: E2A grantee in Ethiopia mobilizes faith-based networks to promote and deliver family planning services. Washington, DC. 2015.

FP2020. Rights and Empowerment Working Group. 2014. Family Planning 2020: Rights and Empowerment Principles for Family Planning. Washington, DC: FP2020.

Gazi, Rukhsana, Alec Mercer, Jahanara Khatun, and Ziaul Islam. Effectiveness of Depot-holders Introduced in Urban Areas: Evidence from a Pilot in Bangladesh. J Health Popul Nutr 2005 Dec;23(4):377-387.

Gulzar, Jamshaid, Moazzam Ali, Chushi Kuroiwa. A social marketing approach to quality improvement in family planning services: a case study from Rawalpindi, Pakistan. BioScience Trends 2008; 2(1):15-21.

Hatt, Laurel, Rebecca Thornton, Barbara Magnoni, and Musaleena Islam. October 2009. Extending Social Insurance to Informal Sector Workers in Nicaragua via Microfinance Institutions: Results from a Randomized Evaluation. Bethesda, MD: Private Sector Partnerships-One project, Abt Associates Inc.

Health Communication Partnership Nepal. Valued Behavior for Healthy Families - A Model for Social Inclusion. October 2006.

Hennink, Monique and Steve Clements. The Impact of Franchised Family Planning Clinics in Poor Urban Areas of Pakistan. Studies in Family Planning, Vol. 36, No. 1 (Mar., 2005), pp. 33-44.

High-Impact Practices in Family Planning (HIP). Financing commodities and services: mobilizing resources to sustain current and future family planning demand. Washington, DC: USAID; 2014 March

High-Impact Practices in Family Planning (HIPs). Adolescent-friendly contraceptive services: mainstreaming adolescentfriendly elements into existing contraceptive services. Washington (DC): USAID; 2015

Hoke, Theresa H, Stephanie B Wheeler, Kelsey Lynd, Mackenzie S Green, Bakolisoa Harimalala Razafindravony, Euge' nie Rasamihajamanana and Paul D Blumenthal. Community-based provision of injectable contraceptives in Madagascar: 'task shifting' to expand access to injectable contraceptives. Health Policy and Planning 2012;27:5259 .

Huber, Douglas, Nika Saeedi and Abdul Khalil Samadi. Achieving success with family planning in rural Afghanistan. Bull World Health Organ 2010;88:227-231. doi:10.2471/BLT.08.059410

IFPS Technical Assistance Project (ITAP). 2012. Social Franchising as a Public-Private Partnership Model- Lessons Learned from the Merrygold Health Network of Uttar Pradesh, India. Gurgaon, Haryana: Futures Group, ITAP.

Institute for Reproductive Health (a). Integrating the Standard Days Method® in Ranchi District, Jharkhand: Key Findings from Household Surveys. February 2008. Washington, D.C.: Institute for Reproductive Health, Georgetown University for the U.S. Agency for International Development (USAID).

Institute for Reproductive Health (b). Lactational Amenorrhea Method (LAM) Projects in India. February 2008. Washington, D.C.: Institute for Reproductive Health, Georgetown University for the U.S. Agency for International Development (USAID).

Institute for Reproductive Health. Working with women's associations to increase acceptability and use of family planning in Mali. 2012. http://irh.org/wp-content/uploads/2013/04/Mali Social Diffusion FAMProject 8.5x11.pdf 
Institute for Reproductive Health. Lactational Amenorrhea Method webpage. http://irh.org/lam/. Accessed June 22, 2017.

Johns Hopkins University Institute for Policy Studies, Center for Civil Society Studies. TOWARD AN ENABLING LEGAL ENVIRONMENT FOR CIVIL SOCIETY Statement of the Sixteenth Annual Johns Hopkins International Fellows in Philanthropy Conference, Nairobi, Kenya, July 4-8, 2004. http://ccss.jhu.edu/wpcontent/uploads/downloads/2011/09/2004-Kenya-Conference-Statement.pdf. Accessed August 7, 2017.

Kanesathasan, Anjala, Laura J. Cardinal, Erin Pearson, Sreela Das Gupta, Sushmita Mukherjee, and Anju Malhotra. Catalyzing Change: Improving Youth Sexual and Reproductive Health through DISHA, an Integrated Program in India. 2008. International Center for Research on Women.

Karim, Ali Mehryar, Timothy Williams, Leslie Patykewich, Disha Ali, Charlotte E. Colvin, Jessica Posner, and Gideon Rutaremwa. The Impact of the African Youth Alliance Program on the Sexual Behavior of Young People in Uganda. Studies in Family Planning 2009; 40[4]: 289-306.

Khatun, Mahmuda, Mahboob-E-Alam, and Quamrun Nahar Nazneen. Assessing Public-Private Reproductive Health Efforts to Reach Young Married Couples in Rural Bangladesh. Int'l. Quarterly of Community Health Education, Vol. 32(1) 73-94, 2011-2012.

Kumar, Jan and Karen Hardee. 2017. "Rights-Based Family Planning: 12 Resources to Guide Programming,” Resource Guide. Washington, DC: Population Council, The Evidence Project.

Lance P., Angeles G, Kamal N. (2012). Smiling Sun Franchise Program (BSSFP) Impact Evaluation Report. Chapel Hill, North Carolina: MEASURE Evaluation.

L’Engle, Kelly L., Heather L. Vahdat, Elizabeth Ndakidemi, Christine Lasway, Trinity Zan. Evaluating feasibility, reach and potential impact of a text message family planning information service in Tanzania. Contraception 87 (2013) $251-256$

Makerere University Department of Social Work and Social Administration (DSWSA). Performance Evaluation of USAID/Uganda's 2009-2014 STRIDES for Family Health Program. 2015.

MEASURE Evaluation and Associates for Community and Population Research. 2005. "2003 BPHC Evaluation Survey." https://www.measureevaluation.org/resources/publications/tr-05-28b?searchterm=2003+BPHC

MEASURE Evaluation and Associates for Community and Population Research. 2006. "2005 Rural NGO Service Delivery Program, (NSDP) Evaluation Survey." https://www.measureevaluation.org/resources/publications/tr$\underline{06-37 a}$

MEASURE Evaluation and Mitra and Associates. 2006. "2005 Urban NGO Service Delivery Program, (NSDP) Evaluation Survey.” https://www.measureevaluation.org/resources/publications/tr-06-37b

Misra, V., P. Ramasankar, L. Durga, J.V.R. Murty, S. Agarwal, and P. Shah. 2007. “Andhra Pradesh, India: Improving Health Services through Community Score Cards." Note No. 1. South Asia Sustainable Development Department, World Bank

Momoh, Gloria. T., Mojisola M. Oluwasanu, Olufemi L. Oduola, Grace E. Delano and Oladapo A. Ladipo. Outcome of a reproductive health advocacy mentoring intervention for staff of selected non-governmental organisations in Nigeria. BMC Health Services Research (2015) 15:314.

Munroe E, Hayes B, Taft J. Private-sector social franchising to accelerate family planning access, choice, and quality: results from Marie Stopes International. Glob Health Sci Pract. 2015;3(2):195-208. http://dx.doi.org/10.9745/ GHSP-D-15-00056. 
Nair, M.K.C., Mini K. Paul, M.L. Leena, Yamini Thankachi, Babu George, P.S. Russell, and H. Vijayan Pillai. Effectiveness of a Reproductive Sexual Health Education Package among School Going Adolescents. Indian J Pediatr (January 2012) 79(Suppl 1):S64-S68.

Ndirangu, Gathari, Anthony Gichangi, Lynn Kanyuuru, Jane Otai, Rose Mulindi, Pamela Lynam, Nancy Koskei, Hannah Tappis, Linda Archer. Using Young Mothers' Clubs to Improve Knowledge of Postpartum Hemorrhage and Family Planning in Informal Settlements in Nairobi, Kenya. J Community Health (2015) 40:692-698.

OHCHR. 2016. General comment No. 22 (2016) on the right to sexual and reproductive health (article 12 of the International Covenant on Economic, Social and Cultural Rights). New York and Geneva: Office of the High Commissioner for Human Rights (OHCHR).

Pande, Rohini, Kathleen Kurz, Sunayana Walia, Kerry MacQuarrie, Saranga Jain. 2006. Improving the Reproductive Health of Married and Unmarried Youth in India. International Center for Research on Women.

Pathfinder International. Citizens Report Card on Family Planning Services in Six Districts of Tanzania. Watertown, MA: Pathfinder International, 2013.

Paxman, John M., Abu Sayeed, Ann Buxbaum, Sallie Craig Huber, and Charles Stover. The India Local Initiatives Program: A Model for Expanding Reproductive and Child Health Services. Studies in Family Planning 2005; 36[3]: 203-220.

Pillsbury, Barbara, Doe Mayer. Women Connect! Strengthening Communications to Meet Sexual and Reproductive Health Challenges. Journal of Health Communication, 10:361-371, 2005

Population Council. Improving Quality of Care in Family Planning. April 2013. http://www.popcouncil.org/news/ improving-quality-of-care-in-family-planning. Accessed March 9, 2017.

Population Services International (2012). Clinical Social Franchising Case Study Series: PSI/Tanzania Familia Network. Washington, DC: PSI.

Raheel H, Karim MS, Saleem S, Bharwani S (2012) Knowledge, Attitudes and Practices of Contraception among Afghan Refugee Women in Pakistan: A Cross-Sectional Study. PLoS ONE 7(11): e48760. doi:10.1371/journal. pone.0048760

Ravindran, T.S. (2010) Privatisation in reproductive health services in Pakistan: three case studies. Reproductive Health Matters 2010;18(36):13-24.

The RESPOND Project. 2013. Expanding contraceptive choice in West Africa: building the capacity of local nongovernmental organizations to program holistically. RESPOND Project Brief No. 15. June. New York: EngenderHealth (The RESPOND Project).

Reyes HLM, Padilla Zuniga K, Billings DL, Blandon MM. Incorporating human rights into reproduc-tive health care provider education programs in Nicaragua and El Salvador. Rev Panam Salud Publica. 2013;34(1):54-9.

Saha et al.: The effect of Self-Help Groups on access to maternal health services: evidence from rural India. International Journal for Equity in Health 2013 12:36.

Santhya, K.G., N. Haberland, A. Das et al. 2008. Empowering married young women and improving their sexual and reproductive health: Effects of the First-time Parents Project. New Delhi: Population Council.

Shattuck, Dominick, Brad Kerner, Kate Gilles, Miriam Hartmann, Thokozani Ng’ombe, and Greg Guest. Encouraging Contraceptive Uptake by Motivating Men to Communicate About Family Planning: The Malawi Male Motivator Project. American Journal of Public Health June 2011, Vol 101, No. 6. Smith, Kimberly and Caroline Quijada. July 2006. Mutual Health Organizations and Reproductive Health in Senegal. Bethesda, MD: The Partners for Health Reformplus Project, Abt Associates Inc. 
Social Franchising for Health. About Social Franchises. 2016. http://sf4health.org/about-social-franchises. Accessed March 9, 2017.

Speizer IS, Corroon M, Calhoun L, Lance P, Montana L, Nanda P, et al. Demand generation activities and modern contraceptive use in urban areas of four countries: a longitudinal evaluation. Glob Health Sci Pract. 2014;2(4):410426. http://www.ghspjournal.org/content/2/4/410

Talukder, Md. Noorunnabi, Ubaidur Rob, Md. Mafizur Rahman. Improving the Quality of Family Planning and Reproductive Tract Infection Services for Urban Slum Populations: Demand-based Reproductive Health Commodity Project. Population Council, Bangladesh. March 2009.

Tavadze, M., D. Bartel and M. Rubardt. Addressing social factors of adolescent reproductive health in the Republic of Georgia. Global Public Health Vol. 4, No. 3, May 2009, 242-252.

Thurston, Sarah, Nirali M Chakraborty, Brendan Hayes, Anna Mackay, and Pierre Moon. Establishing and Scaling-Up Clinical Social Franchise Networks: Lessons Learned From Marie Stopes International and Population Services International. Glob Health Sci Pract. 2015 Jun; 3(2): 180-194. Published online 2015 Jun 12. doi: 10.9745/ GHSP-D-15-00057

Wilder, Jennifer, Rekha Masilamani, and Annie Mathew. Reproductive Health of Young Adults in India: The Road to Public Health. 2006. Pathfinder International.

Wright, Kelsey, Hiba Iqteit, and Karen Hardee. 2015. "Standard Days Method of Contraception: Evidence on Use, Implementation, and Scale-up," Working Paper. Washington D.C.: Population Council, The Evidence Project.

World Health Organization. Media Centre: Health and Human Rights. December 2015. http://www.who.int/ mediacentre/factsheets/fs323/en/. Accessed March 9, 2017.

WHO. 2014. Ensuring Human Rights in the Provision of Contraceptive Information and Services. Geneva: WHO.

WHO. 2017. Quality of Care in Contraceptive Information and Services, Based on Human Rights Standards: A Checklist for Health Care Providers. Geneva: WHO. Licence: CC BY-NC-SA 3.0 IGO. 
The Evidence Project

Population Council

4301 Connecticut Avenue, NW, Suite 280

Washington, DC 20008 USA

tel +1 2022379400

evidenceproject.popcouncil.org 